\title{
Spatial Structure of Cone Inputs to Color Cells in Alert Macaque Primary Visual Cortex (V-1)
}

\author{
Bevil R. Conway \\ Program in Neuroscience and Department of Neurobiology, Harvard Medical School, Boston, Massachusetts 02115
}

The spatial structure of color cell receptive fields is controversial. Here, spots of light that selectively modulate one class of cones (L, M, or S, or loosely red, green, or blue) were flashed in and around the receptive fields of $\mathrm{V}-1$ color cells to map the spatial structure of the cone inputs. The maps generated using these cone-isolating stimuli and an eye-position-corrected reverse correlation technique produced four findings. First, the receptive fields were Double-Opponent, an organization of spatial and chromatic opponency critical for color constancy and color contrast. Optimally stimulating both center and surround subregions with adjacent red and green spots excited the cells more than stimulating a single subregion. Second, red-green cells responded in a luminance-invariant way. For example, red-on-center cells were excited equally by a stimulus that increased L-cone activity (appearing bright red) and by a stimulus that decreased $\mathrm{M}$-cone activity (appearing dark red). This implies that the opponency between $L$ and $M$ is balanced and argues that these cells are encoding a single chromatic axis. Third, most color cells responded to stimuli of all orientations and had circularly symmetric receptive fields. Some cells, however, showed a coarse orientation preference. This was reflected in the receptive fields as oriented Double-Opponent subregions. Fourth, red-green cells often responded to S-cone stimuli. Responses to M- and S-cone stimuli usually aligned, suggesting that these cells might be red-cyan. In summary, red-green (or red-cyan) cells, along with blue-yellow and black-white cells, establish three chromatic axes that are sufficient to describe all of color space.

Key words: color; Double-Opponent; color computation; color constancy; color contrast; receptive field; awake behaving monkey; parallel processing; Hering; cardinal colors; chromatic axes; area 17
Three classes of cones with peak absorptions in the long $(560 \mathrm{~nm})$, medium $(530 \mathrm{~nm})$, and short $(450 \mathrm{~nm})$ wavelengths of light mediate the discrimination of color; they are referred to as L-, M-, and S-cones. The cones are sometimes referred to as red, green, and blue, but each cone class does not code the perception of a single color. Instead, color is mediated by an opponent process (Hering, 1964). This is reflected in the receptive fields of two classes of cells in the lateral geniculate nucleus (LGN), Type I and Type II cells (Fig. 1A,B) (Wiesel and Hubel, 1966). Type II cells are thought to represent the retinal and geniculate origin of the perceptual blue-yellow axis. These cells have spatially simple receptive fields consisting of one region, and stimulation with different wavelengths within this region causes the cell to respond in different ways: blue-on Type II cells would be excited by blue light and suppressed by yellow light (Fig. 1B) (Wiesel and Hubel, 1966; Dacey and Lee, 1994). Because the evidence for red-green Type II cells is paltry (Wiesel and Hubel, 1966; De Monasterio and Gouras, 1975; Dreher et al., 1976; De Monaste-

\footnotetext{
Received Sept. 25, 2000; revised Jan. 18, 2001; accepted Jan. 24, 2001.

This work was supported by Natural Sciences and Engineering Research Council of Canada (B.R.C.) and National Institutes of Health Grant EY 10203 (to Margaret S. Livingstone). This work was done in partial fulfillment of the PhD requirements for the Program in Neuroscience in the laboratory of Margaret S. Livingstone. She provided intellectual and financial support throughout the project. I am grateful to her, David Hubel, and Doris Tsao for many useful discussions. I thank Andrew Stockman for providing cone fundamentals; Arthur Bradley for information about chromatic aberration; Michael Lafratta for machining; David Freeman for computer programming; Tamara Chuprina for animal care; and Steven Macknick for statistics. To Clay Reid, Richard Masland, Carla Shatz, Denis Baylor, Anya Hurlbert, Elio Raviola, Jonathan Trinidad, Claire McKellar, and Tom (Sparky) Davidson for providing useful comments on this manuscript, thank you.

Correspondence should be addressed to Bevil R. Conway, Department of Neurobiology, 220 Longwood Avenue, Boston, MA 02115. E-mail: conway@fas.harvard.edu. Copyright (C) 2001 Society for Neuroscience $0270-6474 / 01 / 212768-16 \$ 15.00 / 0$
}

rio, 1978) (for review, see Rodieck, 1991), Type I cells have been invoked as the origin for the red-green axis. Type I cells are chromatically opponent (Fig. $1 A$ ), although their receptive field centers are much smaller than those of Type II cells and their cone inputs are not entirely spatially colocalized.

Type I and Type II cells would seem to be the building blocks for color perception, but they are by themselves incapable of solving color constancy. Color constancy enables us to determine the color of an object primarily independent of illumination conditions (Land and McCann, 1971). Our ability to do this shows that our perception of the color of an object is not based solely on the light reflected from it but also on the light reflected from surrounding objects (Jameson and Hurvich, 1959, 1989; Land and McCann, 1971). A corollary of this is that surrounding colors profoundly influence perceived color (Albers, 1963; Itten, 1966), a phenomenon known as simultaneous color contrast. The brain might use local color contrast cues to achieve color constancy (Hurlbert, 1999; Kraft and Brainard, 1999) by taking advantage of the invariance (under different illumination conditions) of the ratios of cone activity of adjacent retinal regions (Foster and Nascimento, 1994), but where in the primate brain this takes place is unclear.

Daw (1968) showed that some cells in goldfish retina have receptive fields that are both chromatically and spatially opponent and are therefore capable of computing simultaneous color contrast. In principle, such "Double-Opponent" cells (Fig. 1C) could subserve color constancy (Daw, 1968; Livingstone and Hubel, 1984; Dufort and Lumsden, 1991) by acting as a "wavelength-differencing" system (Zeki, 1993); however, the existence of Double-Opponent cells in the monkey visual system is unclear. Despite intensive efforts, Double-Opponent cells have 
A

$$
\text { B }
$$

C

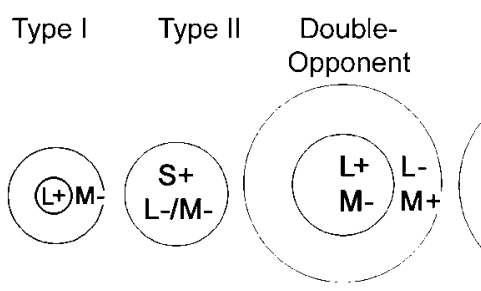

D

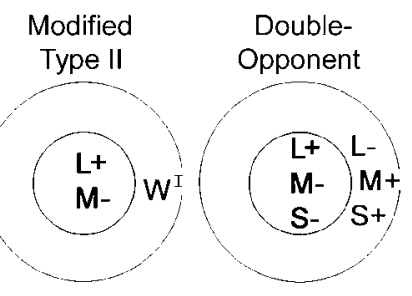

Figure 1. Diagrams of the receptive fields of color-responsive cells. A plus indicates excitation by the given cone, and a minus indicates suppression. $A$, A Type I cell. Type I cells, which are the major cell class in the parvocellular layers of the LGN, have opponent chromatic inputs that are not completely overlapping. Type I cells have very small receptive field centers, often fed by a single cone. $B$, A blue-on/yellow-off Type II cell. Type II cells, found in the koniocellular layers of the LGN, have opponent chromatic inputs that are spatially coextensive. The centers of Type II cells (scaled for eccentricity) are much larger than those of Type I cells and comprise many cones. Type II cells are excited by one color and suppressed by another. This "blue-on" cell would be excited by blue light and suppressed by yellow light. Blue-yellow Type II cells are well described; red-green Type II cells remain to be documented conclusively. $C$, A red-on center Double-Opponent cell. Double-Opponent cells have receptive fields that are both chromatically opponent and spatially opponent. The existence of Double-Opponent cells in the monkey visual system is controversial. $D$, A modified Type II cell. This class is thought by some to exist in V-1 and represent the major class of color-coding cells. $W^{I}$ indicates suppression of center response by all cones. $E$, An example of the organization of color cells reported here [see Note concerning $S$ cone input (Materials and Methods) and Do red-green cells receive S-cone input? (Results) for a discussion of the validity of the S-cone input].

not been found in the monkey retina or the lateral geniculate body (Daw, 1972). Indirect evidence consistent with DoubleOpponent cells has been obtained in V-1 of anesthetized monkeys (Poggio et al., 1975; Michael, 1978; Livingstone and Hubel, 1984), but this has since been interpreted as support for a formulation of these cells as "modified Type II" (Fig. 1D) (Ts'o and Gilbert, 1988). Modified Type II cells were defined as having a color-opponent center and a broadband surround that suppresses any effects of the center; these cells would seem to be incapable of solving color constancy. That Double-Opponent cells as originally described by Daw (1968) do not exist in primary visual cortex (Dow and Gouras, 1973; Vautin and Dow, 1985; Lennie et al., 1990) is the popular sentiment that is now in textbooks (Lennie, 2000).

Here, I directly map the spatial extent of cone inputs to the receptive fields of cortical color neurons in alert macaque. The resulting maps show that the majority of monkey cortical color cells are in fact Double-Opponent (Fig. $1 E$ ).

Parts of this work have been published previously in abstract form (Conway, 2000).

\section{MATERIALS AND METHODS}

General design. Experiments were conducted in alert adult male macaque monkeys. Macaques are a useful model for human color vision because psychophysical studies in them match those of humans (De Valois et al., 1974; Sandell et al., 1979). Moreover, the psychophysical results on human color matching are well predicted from the spectral sensitivities of the macaque cones (Baylor et al., 1987). Monkeys were trained to fixate within a $1^{\circ}$ radius of a fixation spot to receive a juice reward. Data collected when the monkeys moved their eyes outside this tight fixation window was not analyzed. Eye position was monitored with a scleral eye coil (CNC Engineering, Seattle, WA). The eye coil has a spatial resolution of $0.05^{\circ}$ and was calibrated at the beginning of each recording session by having the monkeys look at the center of the monitor and four dots at the corners of the monitor. The monkeys had to maintain fixation for 3-4 sec within the fixation window to receive a juice reward. During periods of stable fixation, average residual eye movements were $<0.25^{\circ}$. These eye movements were compensated using an eye-position correction technique (Livingstone et al., 1996). In generating one-dimensional spacetime maps, this technique affords the measurement of receptive field widths as narrow as $0.2^{\circ}$ (Livingstone and Tsao, 1999). The resolution of the technique is finer than the receptive field subregions of the cells studied here (color cells typically had centers $\sim 0.5^{\circ}$ wide). The maps presented here are the first two-dimensional quantitative receptive field maps of color cells in V-1.

Stimuli were presented (in a dark room) on a computer monitor (Barco Display Systems, Kortrijk, Belgium) $100 \mathrm{~cm}$ from the monkeys' eyes. Neuron responses were recorded extracellularly using fine electropolished tungsten electrodes coated with vinyl lacquer (Frederick Haer Co., Bowdoinham, ME) (Hubel and Wiesel, 1959). Units were isolated using a dual-window discriminator (BAK Electronics, Germantown, MD) after they were amplified and bandpass filtered (1-10 kHz). Only well isolated units (distinguished based on sound and waveform) were analyzed. Only color cells with receptive field centers larger than $0.3^{\circ}$ were studied. Cortical Type I cells, which likely reside in layer $4 \mathrm{C} \beta$ (Livingstone and Hubel, 1984), have tiny receptive field centers $\left(<0.2^{\circ}\right.$ at the eccentricities recorded here) and were not studied. Some cortical cells are well oriented and do not respond to colored spots yet are chromatically tuned (Livingstone and Hubel, 1984; Lennie et al., 1990). These seem to represent a different population of color-coding cells and were not studied here.

Generation of the high cone-contrast cone-isolating stimuli. I used six stimuli: L-plus, L-minus, M-plus, M-minus, S-plus, and S-minus. Each stimulus consisted of a small patch of one color that was surrounded by a full field of a different color. Between these two colors, only the activity of the desired cone was modulated; the plus stimuli increased the activity of a given cone, and the minus stimuli decreased it. Each color was defined by a red-green-blue (RGB) state. The L-plus stimulus, for example, consisted of a small patch of $(\mathrm{L}+)$ state $(255,0,0)$ surrounded by a field of $(\mathrm{L}-)$ state $(0,154,38)$. The $\mathrm{L}$-minus stimulus consisted of a small patch of $(\mathrm{L}-)$ state $(0,154,38)$ surrounded by a field of $(\mathrm{L}+)$ state $(255,0,0)$ (Table 1$)$.

These states were generated as follows. The emission spectra for the three guns (RGB) of the computer monitor used were determined separately using a Photo Research (Chatsworth, CA) PR 650 SpectraScan spectrophotometer. I then calculated a $3 \times 3$ matrix (shown below) representing the activity of each cone type attributable to each gun at 255 by taking the dot product of these spectra with the cone fundamentals (Smith and Pokorny, 1972, 1975), sampled every $4 \mathrm{~nm}$ :

$$
\left(\begin{array}{c}
L_{\text {cone }} \\
M_{\text {cone }} \\
S_{\text {cone }}
\end{array}\right)=\left(\begin{array}{ccc}
R^{\prime *} L^{\prime} & G^{\prime *} L^{\prime} & B^{\prime *} L^{\prime} \\
R^{\prime *} M^{\prime} & G^{\prime *} M^{\prime} & B^{\prime *} M^{\prime} \\
R^{\prime *} S^{\prime} & G^{\prime *} S^{\prime} & B^{\prime *} S^{\prime}
\end{array}\right)\left(\begin{array}{c}
R_{\text {phos }} \\
G_{\text {phos }} \\
B_{\text {phos }}
\end{array}\right)
$$

In this matrix, $\left(L_{\text {cone }}, M_{\text {cone }}, S_{\text {cone }}\right)$ are the relative cone activities for any combination of phosphors $\left(R_{\text {phos }}, G_{\text {phos }}, B_{\text {phos }}\right) ;\left(R^{\prime}, G^{\prime}\right.$, and $\left.B^{\prime}\right)$ are the spectra of maximum phosphor activity and $\left(L^{\prime}, M^{\prime}\right.$, and $\left.S^{\prime}\right)$ are the relative cone absorption spectra. * indicates dot product. (The inverse of this matrix yielded the phosphor values for specified cone activities.) The matrix obtained is given below:

$$
\left(\begin{array}{l}
L_{\text {cone }} \\
M_{\text {cone }} \\
S_{\text {cone }}
\end{array}\right)=\left(\begin{array}{lll}
129.7517 & 131.6641 & 50.6336 \\
26.4562 & 83.8079 & 46.1203 \\
2.4618 & 6.0469 & 178.0737
\end{array}\right)\left(\begin{array}{c}
R_{\text {phos }} \\
G_{\text {phos }} \\
B_{\text {phos }}
\end{array}\right)
$$

Using this matrix, I calculated relative gun values that would yield the two states $[(+)$ and $(-)]$ for each cone class (Table 1$)$. The rationale for developing high cone-contrast cone-isolating stimuli was simple. For the L-stimulus, for example, I used the maximal red phosphor during the $(\mathrm{L}+)$ state and then matched the activity of the M- and S-cones produced by the red phosphor with the green and blue phosphors during the $(\mathrm{L}-)$ state. I ended up with six relative gun values: three for the $(\mathrm{L}+)$ state and three for the $\left(\mathrm{L}^{-}\right)$state (Table 1$)$. These gun values cannot be used directly because they assume that the luminance function for each gun is linear, which is not the case (Fig. 2). Therefore, the relative gun values were converted to luminance values [ $\mathrm{gun}\left(\mathrm{cd} / \mathrm{m}^{2}\right)$ in Table 1] and then to the conventional $0-255$ values [gun $(0-255)$ in Table 1] using polynomials (Fig. 2, lines) fit to the empirically derived gun luminance functions (Fig. 2, circles, crosses, and triangles) (Wandell, 1995).

To verify that these derived values were actually cone-isolating, I 
Table 1. Phosphor values and cone activities of the high cone-contrast cone-isolating stimuli

\begin{tabular}{|c|c|c|c|c|c|c|}
\hline & \multicolumn{3}{|l|}{$(+)$ State } & \multicolumn{3}{|c|}{ (-) State } \\
\hline & $\mathrm{L} / \mathrm{R}$ & $\mathrm{M} / \mathrm{G}$ & $\mathrm{S} / \mathrm{B}$ & $\mathrm{L} / \mathrm{R}$ & $\mathrm{M} / \mathrm{G}$ & $\mathrm{S} / \mathrm{B}$ \\
\hline \multicolumn{7}{|l|}{ L-isolating } \\
\hline Relative gun & 100 & 0 & 0 & 0 & 31.4 & 0.32 \\
\hline Relative cone & 12975 & 2646 & 246 & 4150 & 2646 & 246 \\
\hline Gun $\left(\mathrm{cd} / \mathrm{m}^{2}\right)$ & 44.32 & 0 & 0 & 0 & 18.9 & 0.08 \\
\hline Gun $(0-255)$ & 255 & 0 & 0 & 0 & 156.8 & 55 \\
\hline Cone activation & 130.955 & 27.054 & 2.652 & 43.484 & 27.128 & 2.679 \\
\hline Final gun & 255 & $\mathbf{0}$ & $\mathbf{0}$ & $\mathbf{0}$ & 154 & 38 \\
\hline \multicolumn{7}{|l|}{ M-isolating } \\
\hline Relative gun & 0 & 100 & 0 & 100.7 & 0 & 2.005 \\
\hline Relative cone & 13166 & 8381 & 605 & 13166 & 2756 & 605 \\
\hline Gun $\left(\mathrm{cd} / \mathrm{m}^{2}\right)$ & 0 & 59.63 & 0 & 44.32 & 0 & 0.51 \\
\hline Gun $(0-255)$ & 0 & 254.3 & 0 & 255 & 0 & 62.6 \\
\hline Cone activation & 131.143 & 83.479 & 6.043 & 131.312 & 27.500 & 6.003 \\
\hline Final gun & $\mathbf{0}$ & 252 & $\mathbf{0}$ & 255 & $\mathbf{0}$ & 55 \\
\hline \multicolumn{7}{|l|}{ S-isolating } \\
\hline Relative gun & 64 & 0 & 255 & 0.9011 & 160.2 & 0 \\
\hline Relative cone & 21216 & 13454 & 45566 & 21216 & 13454 & 0.0971 \\
\hline Gun $\left(\mathrm{cd} / \mathrm{m}^{2}\right)$ & 11.12 & 0 & 25.6 & 0.157 & 37.735 & 0 \\
\hline Gun $(0-255)$ & 143.6 & 0 & 255 & 56.3 & 211.1 & 0 \\
\hline Cone activation & 86.903 & 54.218 & 181.625 & 87.141 & 54.628 & 3.933 \\
\hline Final gun & 148 & 0 & 255 & 52 & 209 & 0 \\
\hline
\end{tabular}

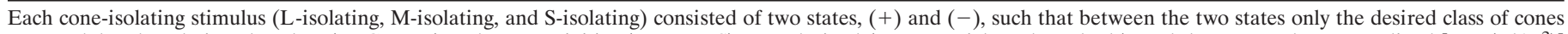

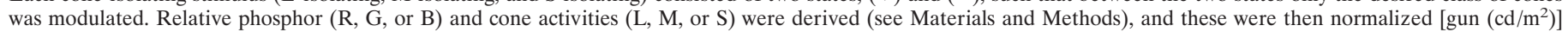

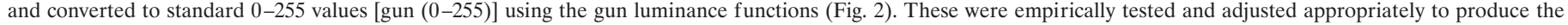
gun and cone activities of the stimuli as they appeared to the monkeys (values in bold).

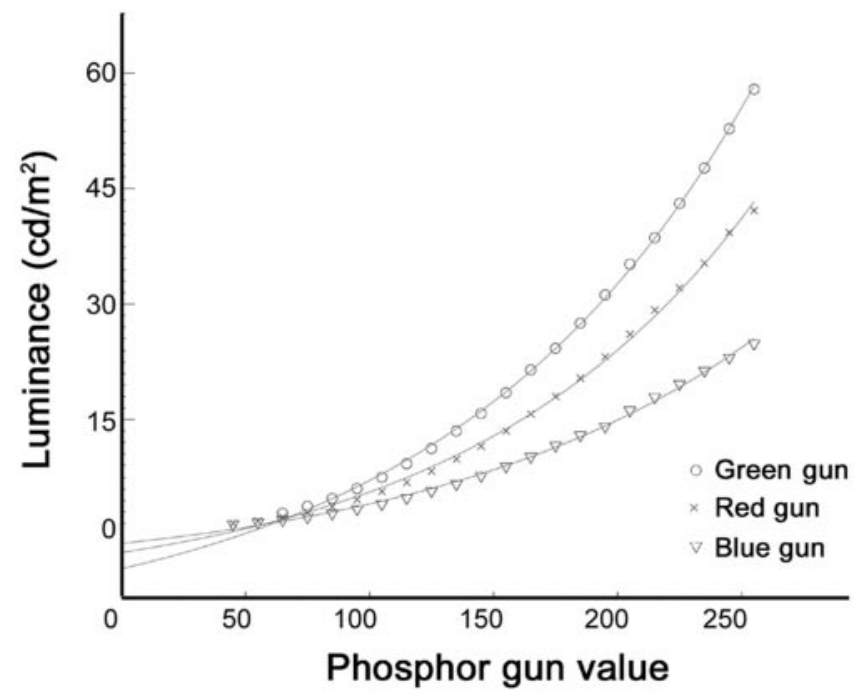

Figure 2. Gun luminance function. The luminance of the computer monitor (in candelas per square meter) was measured separately for each gun. Crosses, Red gun; circles, green gun; triangles, blue gun. These values were fit by polynomials (lines). This enabled me to normalize the gun values, which was necessary in generating the cone-isolating stimuli (see Materials and Methods).

measured the emission spectra (separately) for each state. I calculated the cone activities elicited by these two states by taking the dot product of their emission spectra with the three cone fundamentals. This is analogous to the approach used by others (Chichilnisky and Baylor, 1999). A given stimulus always modulated the desired cone class much more than it modulated either of the other two cone classes. To improve them further, however, I tweaked the gun values of the two states and recalculated the cone activities until the undesired cone classes had
Table 2. Relative rod activity produced by the high cone-contrast stimuli (see Materials and Methods)

\begin{tabular}{lll} 
& $(+)$ State & $(-)$ State \\
\hline L-isolating & 313.8 & 267.7 \\
M-isolating & 797.8 & 337.3 \\
S-isolating & 861.1 & 400.2
\end{tabular}

modulation indices of $<0.4$. These tweaked gun values and the resulting cone values are listed as "final gun" and "cone activation" (Table 1). The cone modulation index $=(($ maximum cone activity - minimum cone activity $) /($ maximum cone activity + minimum cone activity) $) * 100$. The $\mathrm{L}$ stimuli had a modulation index of 50.1, $\mathrm{M}$ of 50.4, and $\mathrm{S}$ of 95.8. The cone isolation was checked periodically (every month or so), and appropriate minor changes were made to the phosphor values. A final confirmation that the L-cone stimulus was cone-isolating was obtained by presenting it to a protanope, who found it almost invisible.

Under the stimulus conditions used, a significant contribution by the rods is unlikely because the rods are probably saturated. The relative activity of the rods under the different stimulus conditions was calculated by taking the dot product of the scotopic luminosity function (every 4 $\mathrm{nm}$ ) and the emission spectra of each of the states (Table 2). These values can be compared with the cone activations in Table 1 . The relative rod values are very high, reflecting the high mean luminance under all stimulus conditions. The luminance (in candelas per square meter) for each state was approximately $\mathrm{L}(+), 44 ; \mathrm{L}(-), 19 ; \mathrm{M}(+), 60 ; \mathrm{M}(-), 45$; $\mathrm{S}(+), 37$; and $\mathrm{S}(-), 38$. The illuminance limit for human rods is 1800 scotopic trolands (Hess and Norby, 1986), which is equivalent to 7200 photons per receptor per second (Spillman and Werner, 1990). The luminance of the S-cone stimulus $\left(37 \mathrm{~cd} / \mathrm{m}^{2}\right)$ corresponds to $\sim 10,400$ photons absorbed per receptor per second $\left(\mathrm{cd} / \mathrm{m}^{2} * 10 * \mathrm{pi} *\right.$ radius of pupil $(\mathrm{mm})^{2}$ (pupil is $\left.\sim 3 \mathrm{~mm}\right)$ ), putting the S-cone stimulus securely in the photopic range. Qualitatively, all of the stimuli appear bright and vividly colored.

Conventional cone-isolating stimuli presented on a constant adapting 
background were also generated (Reid and Shapley, 1992). Cone modulation indices for these stimuli were $\mathrm{L}$ of $33.3, \mathrm{M}$ of 41.2, and $\mathrm{S}$ of 94.7. The constant gray background was (R, G, B) $175,143,126 ; \sim 17 \mathrm{~cd} / \mathrm{m}^{2}$ (Fig. 2). The results using these stimuli were comparable with those using the high cone-contrast stimuli (see Figs. 6, 10).

Note concerning the S-cone-isolating stimulus. The cone-isolating stimuli were based on the cone fundamentals of Smith and Pokorny (1972, 1975). These fundamentals are derived from color-matching functions for the central $2^{\circ}$. The corresponding region of the retina is protected by macular pigment. Macular pigment, which absorbs a significant amount of light of shorter wavelengths, is densest in the fovea and falls toward the periphery (Polyak, 1957). Cone-isolating stimuli based on Smith and Pokorny $(1972,1975)$ are therefore best applied to cells whose receptive fields are in the central $2^{\circ}$. Macular pigment interferes minimally with Land $\mathrm{M}$-cone isolation because the macular pigment absorbs in the shorter wavelengths $(400-500 \mathrm{~nm})$, and L- and M-cone-isolating stimuli use the red and green phosphors, which emit scarcely in the shorter wavelengths. However, macular pigment might pose a problem in interpreting responses to S-cone-isolating stimuli if the receptive fields are outside of the macular pigment region of the retina. To test this, two cells having receptive fields at $5^{\circ}$ were mapped with cone-isolating stimuli that used $10^{\circ}$ fundamentals (Stockman and Sharpe, 2000). The maps were qualitatively identical to those generated using cone-isolating stimuli based on Smith and Pokorny $(1972,1975)$. All cells recorded were between 2.5 and $5^{\circ}$ eccentricity.

The effects of lateral chromatic aberration should be considered. Lateral chromatic aberration (the displacement on the retina of the blue image resulting from the greater refraction of short wavelength light) is likely not a problem for two reasons. First, assuming the monkeys have pupils that are approximately aligned with the visual axis, as is the case for the average human, lateral chromatic aberration would account for shifts of $<1.3$ arc minutes at $5^{\circ}$ eccentricity (Thibos et al., 1990). (All cells studied were within $5^{\circ}$ of the fovea.) This amount of shift is small compared with the diameter of the receptive fields of the color cells $\left(\sim 1.5^{\circ}\right)$. Second, there was no systematic shift of the blue map for cells in a given receptive field location as would be expected if lateral chromatic aberration were underlying the spatial shifts between the maps.

The effects of longitudinal chromatic aberration should also be considered. Given that the eyes are generally focused in the yellow, the S-cone stimulus (which uses a lot of blue light) might be defocused. This longitudinal (or axial) chromatic aberration would have two effects. First, it would result in a stimulus spot that was slightly larger than an L- or M-isolating stimulus spot of nominally the same size. If this were a major problem, then the spatial distribution of the response to the S-cone stimulus might not be interpretable. This is likely not a problem because spatial structure is discernable in the maps; the suppression in the center of a red-on-center/cyan-off-center cell is clear (see Fig. 4A). However, blurring may still pose some problem for the S-cone stimulus because it would result in desaturating the shorter wavelengths that contribute to the S stimulus. If blurring caused significant desaturation, I would have overestimated the impact of the $(\mathrm{S}+)$ state (which uses maximal blue gun) on the L- and M-cones. Thus, the activity of the L- and M-cones would be slightly higher during the $(\mathrm{S}-)$ state than during the $(\mathrm{S}+)$ state, because the $\mathrm{G}$ and $\mathrm{R}$ phosphors are used during the $(\mathrm{S}-$ ) state and these phosphors are not desaturated. Thus, the $(\mathrm{S}-)$ state would not only decrease the activity of the $\mathrm{S}$-cones relative to their activity during the $(\mathrm{S}+)$ state, but it would also increase the activity of the M- and L-cones. This would seem not to be a problem in the present study because I only studied cells that gave opponent responses to M-plus and L-plus stimuli: the increased activity of the L-cones would cancel the effect of the increased activity of the M-cones. However, the blue gun stimulates the $\mathrm{L}$-cones slightly more than it stimulates the M-cones (the blue gun activates the L-cones by 50.6336 and the M-cones by 46.1203 relative units; see matrix above). Thus, the effect of chromatic aberration during the $(\mathrm{S}+)$ state would be slightly greater for the L-cones than for the M-cones, and consequently the calculated activity of the L-cones would be overestimated slightly more than the calculated activity of the $\mathrm{M}$-cones. If this were significant, it would mean that the $(\mathrm{S}-)$ state would have acted slightly more like an L-plus stimulus than like an M-plus stimulus. Given this, one would expect red-green cells that do not receive any S-cone input to respond (probably weakly) to an S-minus stimulus in a way predicted by the L-plus stimulus. A recent preliminary study contends that the effects of longitudinal chromatic aberration are insignificant (Cottaris et al., 2000).

Stimulus presentation. The stimulus used to generate a given map involved presenting a single small patch of cone-isolating light $(\sim 0.4 \times$ $0.4^{\circ}$ square) at random locations in and around the receptive field of the cell while the monkey fixated. The adapting background covered the full 21 inch monitor $\left(\sim 20^{\circ}\right.$ of visual angle $)$. Because the adapting backgrounds were different for each stimulus in a stimulus pair (e.g., L-plus and L-minus have different adapting backgrounds), the two maps for each pair were generated separately from different stimulus runs. The size of the cone-isolating patch was optimized for each cell. Stimuli were presented for $30-100 \mathrm{msec}$ in each location, and there was a $13 \mathrm{msec}$ refresh delay before presentation in a new location. The patch flickered over an area of at least $3 \times 3^{\circ}$ centered on the receptive field, an area sufficient to sample the receptive field center and surround. The size of the stimulus was not critical, as long as the stimulus was smaller than the receptive field center. I confirmed this by comparing maps obtained from the red-on-center cell shown in Figure $4 A$ (using $0.4 \times 0.4^{\circ}$ square stimuli) with maps obtained using smaller stimuli $\left(0.15 \times 0.15^{\circ}\right.$ square $)$. Similar receptive field sizes were obtained. Maps reflect stimuli positions $50-70 \mathrm{msec}$ before each action potential and are smoothed with a Gaussian filter. The 50-70 msec delay corresponds to the visual latency of the cell. Each map is an average of at least 40 (and usually many more) presentations everywhere in the receptive field. The maps shown in Figures $4,5,8$, and $10 \mathrm{~A}$ are linear with respect to cell response; peak responses correspond to the most saturated colors and are given in the figure legends or the adjacent poststimulus time histograms (PSTHs). Each map took from 15-45 min and usually consisted of at least 1500 spikes. Except in Figures 6 and 10, $C$ and $E$, the response maps are colored to facilitate linking with the stimulus. Thus, an L-plus map and an M-minus map are both red, because the L-plus stimulus looks bright red and the M-minus stimulus looks dark red. Similarly, the M-plus and L-minus maps are both green. The S-plus map is blue, and the S-minus map is yellow.

Data quantification. The response maps were quantified by generating PSTHs corresponding to stimuli presentation to the most active region of the center (see Fig. 7, black traces) and the surround (see Fig. 7, gray traces). The sizes of the regions from which spikes were collected were defined by the size of the stimulus used to map each cell; the activity was normalized for the number of stimulus presentations. Cell response was determined by subtracting the background rate from the peak. Background measurements were determined based on the first $40 \mathrm{msec}$ of the PSTHs. SEs of the measurement (peak activity-background activity) are given in Figure 9 when they are larger than the size of the symbols.

\section{RESULTS}

To identify and map color cells, cortical cells were tested with stimuli that selectively modulate a single class of cones. These cone-isolating stimuli can be made with the silent substitution method of Rushton (Donner and Rushton, 1959) (for review, see Estevez and Spekreijse, 1982). Typically, such stimuli involve a constant gray adapting background on which stimuli either increase (a plus stimulus) or decrease (a minus stimulus) the activity of a given cone class (Reid and Shapley, 1992). The gray background provides an adapting field that is the same for all cone-isolating stimuli, but it limits the cone contrast that can be achieved. To boost the cone contrast in the present study, coneisolating stimuli with differing adapting backgrounds were used (see Materials and Methods). The validity of using these high cone-contrast stimuli was explicitly demonstrated by showing that the results are comparable with results obtained using coneisolating stimuli presented on a constant gray background (see Fig. 6). A plus stimulus for each cone class consisted of a small patch of light that selectively activates that cone $[(+)$ state] surrounded by a field of light that selectively inactivates that cone [(-) state] (Table 1). The L-plus stimulus, for example, looked like a patch of bright red light surrounded by a field of darker bluish-green. A minus stimulus was a small patch of $(-)$ state surrounded by a field of $(+)$ state. The L-minus stimulus looked like a patch of dark bluish-green surrounded by a field of bright red. The L- and M-cone-isolating stimuli had nearly identical modulation indices, but the S-cone-isolating stimulus had a much 

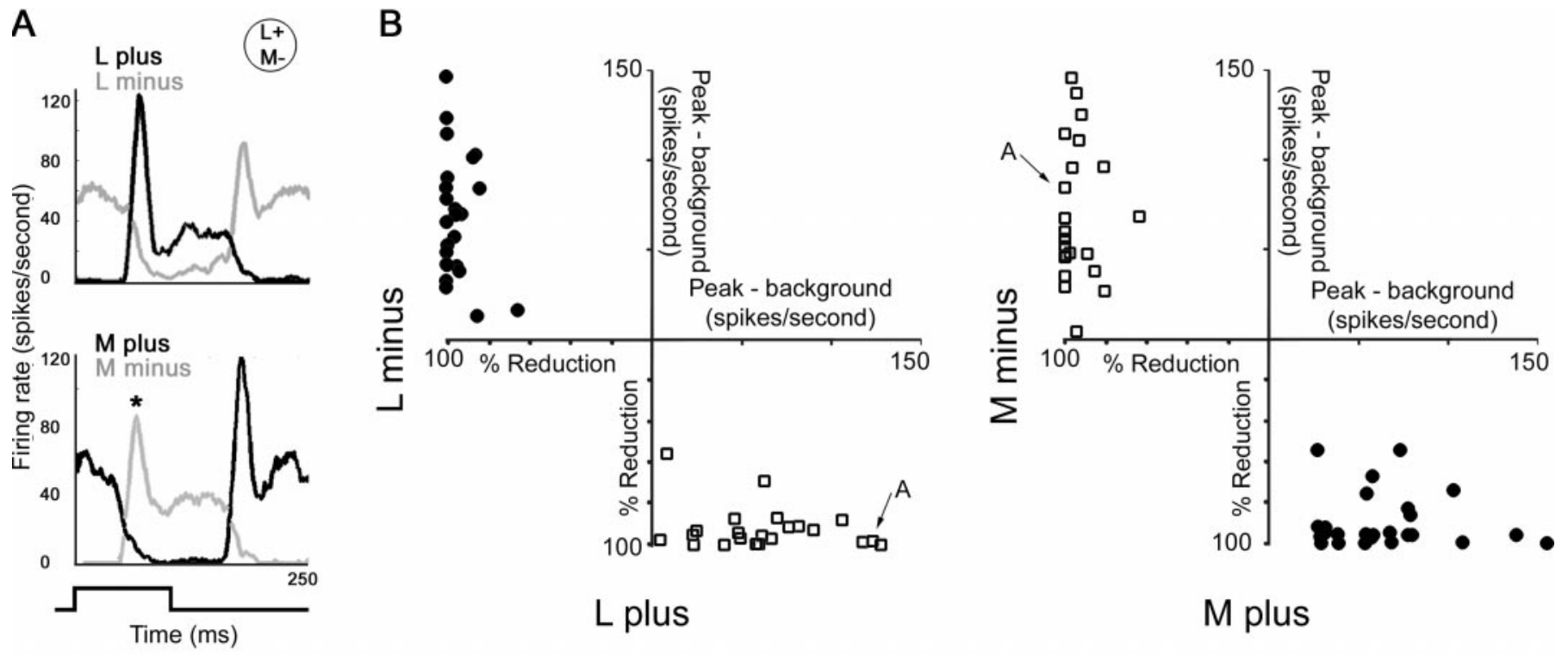

Figure 3. Modulation of cell activity in response to flashes of cone-isolating light presented in the center of color cell receptive fields. A plus stimulus selectively increased the activity of a given class of cones but maintained constant activity of the other two classes. A minus stimulus selectively decreased the activity (see Materials and Methods and Table 1). A, PSTHs for an L+/M-centered cortical cell. The cell was excited by the L-plus stimulus (top plot, black trace) and suppressed by the L-minus stimulus (top plot, gray trace); it also gave opponent responses to the M-plus stimulus (bottom plot, black trace) and the M-minus stimulus (bottom plot, gray trace). This cell gave opponent responses to the L-plus and M-plus stimuli, identifying it as a color cell. A luminance cell would respond with the same sign (excitation or suppression) to L-and M-plus stimuli. The stimulus was a $\sim 1 \times 1^{\circ}$ square centered on the receptive field; it was on for $100 \mathrm{msec}$ (indicated at bottom). The peak response to M-minus (asterisk) was used as a measure of the full extent of suppression by M-plus (see Quantification of double opponency in Results). B, Responses determined from PSTHs for 47 color cells screened as in $A$. Modulation in response to L-plus and L-minus (left graph) and in response to M-plus and M-minus (right graph) is shown: red-on-center cells (open squares) and green-on-center cells ( filled circles). The response was categorized as suppression (e.g., response to L-minus in $A$ ) or excitation (e.g., response to L-plus in $A$ ). Suppression was then quantified as a percentage of reduction of background, in which background was calculated based on the first $40 \mathrm{msec}$ of the PSTH. Excitation was quantified as (peak - background) (in spikes per second). The cell whose PSTH is given in $A$ is identified.

higher index (see Materials and Methods). An additional advantage of using the high cone-contrast stimuli is that they use a higher mean luminance than conventional stimuli presented on gray backgrounds. This helps saturate the rods.

\section{Screening for color cells}

Cortical cells were screened with cone-isolating stimuli; every cortical cell encountered was tested with alternating flashes of a small patch $\left(<1 \times 1^{\circ}\right)$ of L-plus and M-plus cone-isolating light centered on the receptive field. The patch was manually guided in and out of the receptive field to find the cell center. (Cells were also tested with spots and oriented flashed and moving bars of various colors.) A cell was designated a color cell if it responded vigorously to small spots of colored light and if the L-plus and the M-plus stimuli produced opposite responses (excitation vs suppression) (Fig. 3A). I screened for red-green cells because, in the cortex, they are more common than blue-yellow cells (Wiesel and Hubel, 1966; Livingstone and Hubel, 1984; Ts'o and Gilbert, 1988). Simple luminance cells would produce similar responses to the M-plus and L-plus stimuli. Complex cells, which are by far the major cell type in V-1, produced weak and transient responses at the onset and offset of all cone-isolating stimuli. I screened $\sim 615$ single units in the primary visual cortex to obtain 65 red-green color cells. All cells were between 2.5 and $5^{\circ}$ eccentricity. Most showed a complete suppression of firing to one of the two stimuli (Fig. 3A), making them easily recognizable on an audio monitor. Cells were characterized as either L-plus on (i.e., red-on-center) or M-plus on (i.e., green-on-center). Thirty-six of 65 were red-on, and 29 of 65 were green-on. Based on physiological criteria, cells were found both above and below layer 4C. Most of the cells were strongly monocular, consistent with previous reports (Michael, 1978). PSTHs generated using these screening stimuli were collected for 47 cells (Fig. 3B); 22 of 47 cells were red-on-center (Fig. $3 B$, open squares), and 25 of 47 were green-on-center (Fig. $3 B$, filled circles). Because my electrode was not intracellular, I cannot distinguish between the specific mechanism of opening chloride channels (i.e., inhibition) and withdrawal of excitation. For this reason, I prefer the less specific term "suppression" (rather than "inhibition") to describe a decrease of the activity of a cell in response to a stimulus.

\section{Spatial maps of the cone inputs to color cells: testing the surround for double opponency}

After identifying a color cell, I mapped it with patches of coneisolating stimuli that were smaller than those used for screening the color cells. The stimulus for mapping the L-plus response, for example, looked like a single small patch (smaller than the receptive field center) of bright red light flickering on a full field of darker bluish-green in and around the receptive field. The only cones that were modulated during the stimulus were the L-cones, and their activity was increased everywhere the small patch of bright red landed. The stimulus for mapping the L-minus response looked like a single small patch of darker bluish-green flickering on a full field of bright red. During this stimulus, the only cones that were modulated were also the L-cones, but their activity was decreased everywhere the small patch of bluish-green landed. Note that, because each stimulus in a stimulus pair (plus and minus) had a different adapting background, they had to be mapped separately; the maps are therefore constructed from separate stimulus runs. This is in contrast to other approaches in 
which, for example, L-plus and L-minus are presented simultaneously on a gray background and the resulting maps are generated by subtracting the response to minus from the response to plus.

Complete mapping included six maps: L-plus, L-minus, M-plus, M-minus, S-plus, and S-minus. Time permitting, I also collected the two luminance maps: the map of black on a white background and the map of white on a black background. In addition, to demonstrate the validity of using stimuli presented on differing adapting backgrounds, several cells were also tested with stimuli presented on gray backgrounds ("low cone-contrast stimuli") (see Fig. 6).

Two-dimensional spatial maps of the receptive fields were generated using the eye-position-corrected reverse correlation technique of Livingstone et al. (1996) (see Materials and Methods). The response maps reflect the average position of the stimulus before each spike, accounting for the latency of the cell, and reveal the spatial structure of the receptive fields. During mapping, the waveform of a the cell was monitored to ensure that all maps were derived from a single cell. Of the 65 cells screened for color, the complete ensemble of maps was collected for 24 cells. In 25 of the remaining cells, at least three of the six maps were obtained, permitting an assessment of the cone inputs to the surround; the data from these cells support the conclusions based on the 24 cells with complete maps. Two red-on-center cells with complete maps are shown in Figure 4. In these maps, higher cell responses are indicated by more saturated colors, and black represents zero spikes per second. The background firing rate for each condition has not been subtracted.

As expected for a red-on-center cell, the receptive field center was excited by the L-plus stimulus (Fig. $4 A$, top left panel). The center was chromatically opponent, as shown by the suppression by M-plus spots in this region (Fig. $4 A$, middle left panel). The $\mathrm{S}$-plus stimulus presented in the center of the receptive field was also suppressive (Fig. 4A, bottom left panel). Suppression in the plus stimulus maps can be inferred by the minus stimulus maps, which reveal a similar spatial distribution but produce excitation. For example, the center, which was suppressed by M-plus, was excited by M-minus. A second red-on-center cell at a similar eccentricity is shown (Fig. 4B). Both cells were Double-Opponent; L-plus, M-minus, and S-minus excited these cells in the center of their receptive fields. In spatial and chromatic opponency, these cells were excited by L-minus, M-plus, and S-plus in the surround. This pattern of response is summarized in the diagram (Figs. $1 E$, 4, top). The surround response to M-plus, S-plus, and L-minus is not attributed simply to a higher background firing rate for those stimulus conditions. This is clear in the maps because the firing rate attenuates in the region of the maps outside the surround.

Surround strength varied between cells. A red-on-center cell with a strong surround (Fig. $5 A$ ) and a green-on-center cell with a very weak surround illustrate this (Fig. $5 B$ ). As with Figure 4, more saturated colors represent stronger responses, and black represents zero spikes per second. The response maps represent the actual firing rate and are not corrected for the variability in background firing rate between stimulus conditions. Thus, the overall brightness of each map varied. This can be misleading because the elevated background activity produced by some of the stimulus conditions can be misinterpreted as a strong surround (Fig. $5 B$ ). To be significant, the surround must drop off in the periphery, as is clear for the cell in Figure $5 A$ but not as clear for the cell in Figure $5 B$. The variability between backgrounds was accounted for in quantifying the responses (see Fig. 9). In earlier studies, the cell shown in Figure $5 B$ might have been called a Type II cell (a cell having no surround), or a $3 / 4$ DoubleOpponent cell (a cell having a surround fed by a single cone class), but the mapping technique used here allowed a quantitative assessment of the cone inputs to the surround, and although they are weak, they are chromatically opponent (Fig. 5C). The excitation by L-plus in the surround is clear as a peak in the poststimulus time histogram at $\sim 70 \mathrm{msec}$ (Fig. $5 \mathrm{C}$, top PSTH, gray trace). The suppression by M-plus in the surround is evident as a dip (Fig. 5C, middle PSTH, gray trace).

Time permitting, the luminance maps were collected (Figs. $4 A$, $5 B)$. A perfect balance of opponent cones would predict no response to luminosity (i.e., broadband light). Some DoubleOpponent cells, however, were not perfectly balanced. This was the case for the red-on-center cell (Fig. 4A), which gave a response to black. It is difficult to interpret these luminance maps without making assumptions about how the cone inputs are summed, especially given the fact that the white stimulus (all guns set to 255) does not appear perfectly white and does not modulate the cones in a way predicted by the sum of the three separate plus stimuli. Instead, the cone interactions were tested directly with a different set of experiments (see Cone interactions below and Fig. 10).

It has been suggested that cone-isolating stimuli presented on gray backgrounds are not effective for driving cortical color cells because of the limitation on cone contrast (D. Hubel and M. Livingstone, personal communication). To overcome this potential problem, high cone-contrast stimuli were used for spatial mapping (Figs. 4, 5). A few cells were also tested with stimuli presented on constant adapting gray backgrounds (low conecontrast stimuli) to test the validity of using the high cone-contrast stimuli. The low cone-contrast stimuli elicited responses, but the maps from the high cone-contrast stimuli were typically clearer (Fig. 6A). For example, the annulus of excitation produced by the M-plus stimulus for a red-on-center cell is readily evident for the high cone-contrast map but not so clear for the low cone-contrast map (Fig. $6 A$; this is the same cell as that shown in Fig. $5 A$ ). Note that the color of the maps in Figure 6, unlike the color of the maps in the other spatial maps (Figs. 4, 5), has nothing to do with the color of the stimulus but reflects the firing rate. The number of stimulus presentations was the same between the low and high cone-contrast maps, and the colored firing rate scale bar is the same for all four maps shown in Figure $6 A$. The spatial opponency was only revealed with the low cone-contrast stimuli when the minus response map was subtracted from the plus response map (Fig. 6B), making the low cone-contrast stimuli less suitable to a direct assessment of the spatial receptive field structure.

All cells showed opposite responses within each receptive field subregion for every stimulus pair (plus and minus). Both the excitatory and suppressive responses were often sustained, as evident in the time course for a green-on-center cell (Fig. 7). The PSTHs (Fig. 7) were extracted from the reverse correlation data and correspond to stimulus presentation in the center (black traces) and surround (gray traces) for the plus stimuli (left plots) and minus stimuli (right plots). An off-discharge after release of suppression was usually evident (e.g., L-plus center in Fig. 7).

Another green-on-center cell is illustrated in Figure 8. The double opponency is clear from the PSTHs (Fig. $8 B$; conventions as in Fig. 7). Suppression is evident as a dip from baseline activity, which was highlighted by a discharge upon release of suppression (for example, the large peak beginning at $200 \mathrm{msec}$ in the black trace, bottom left plot). The S-plus stimulus produced remarkably potent suppression in this cell, lasting almost twice the stimulus 


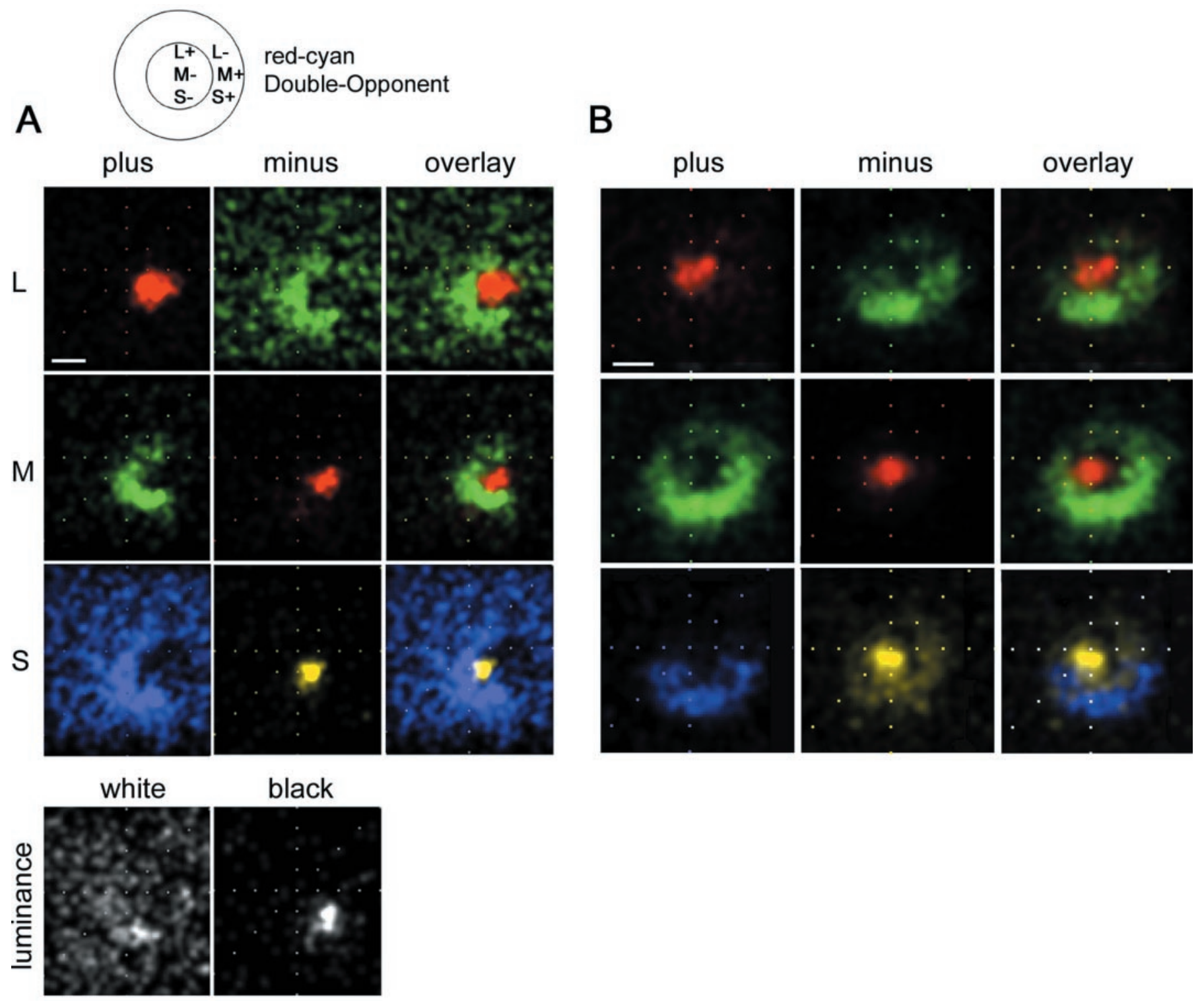

Figure 4. Receptive fields of two red-on-center/green-on-surround Double-Opponent cells recorded in alert macaque V-1. A, A small patch of cone-isolating light was flashed at random locations in and around the receptive field; response maps were generated using an eye-position-corrected reverse correlation technique (see Materials and Methods). The maps reflect the average stimulus position that preceded each spike and are corrected for eye position and for the visual latency. L-plus, M-plus, and S-plus, left column; L-minus, M-minus, and S-minus, middle column; and overlay, right column. The background firing rate has not been subtracted from these maps. Black in these maps represents a firing rate of zero spikes per second; more intense responses are represented as more saturated colors. Peak firing rates (spikes per second) were as follows: L-plus, 62; L-minus, 20; M-plus, 35; M-minus, 47; S-plus, 16; S-minus, 71; white, 21; black, 27. Stimulus size was $0.4 \times 0.4^{\circ}$. This cell was $4^{\circ}$ peripheral. Scale bar (in $A$ and $B$ ), $0.5^{\circ}$. The coloring of the maps does not match that of the stimuli. The L-plus and M-minus maps are colored red because the stimulus in both cases appears red; the L-plus stimulus is a bright red (on a dark bluish-green), and the M-minus is a dark bluish-red (on a bright green background). $B$, Response maps for a second red-on-center Double-Opponent cell. Peak firing rates (spikes per second) are as follows: L-plus, 67; L-minus, 45; M-plus, 77; M-minus, 57; S-plus, 23; S-minus, 30 . This cell was $5^{\circ}$ peripheral. Stimulus size was $0.4 \times 0.4^{\circ}$.

duration. Note that, in contrast to the cells presented in Figures 4 and 5 , the S-cone input in this cell aligns in space and sign with the L-cone input.

The spatial maps had sufficient resolution to assess whether the cone contribution to the surround was homogeneous. Often the surrounds were nonuniform; for example, the contribution of the M-cones to the surround of the red-on-center cell shown in Figure 4 was not perfectly annular but crescent-shaped. The full range of surrounds exhibited by Double-Opponent cells is shown by comparing the extent of the surround in Figure $5 A$ (a full annulus), in Figure $4 A$ (a crescent), and in Figure $10 A$ (an adjacent, oriented field). Nine of 49 cells showed a receptive-field organization similar to that of the cell shown in Figure $10 \mathrm{~A}$, in which the subregions were not suitably described as center and surround but rather as adjacent subregions. Moreover, each of these subregions was coarsely oriented.

\section{Quantification of double opponency}

One way to quantify the response of a cell is to evaluate the change in the activity of the cell as a proportion of its background activity (Fig. $3 B$ ). The background activity was determined based on the activity for the first $40 \mathrm{msec}$ of the poststimulus time 


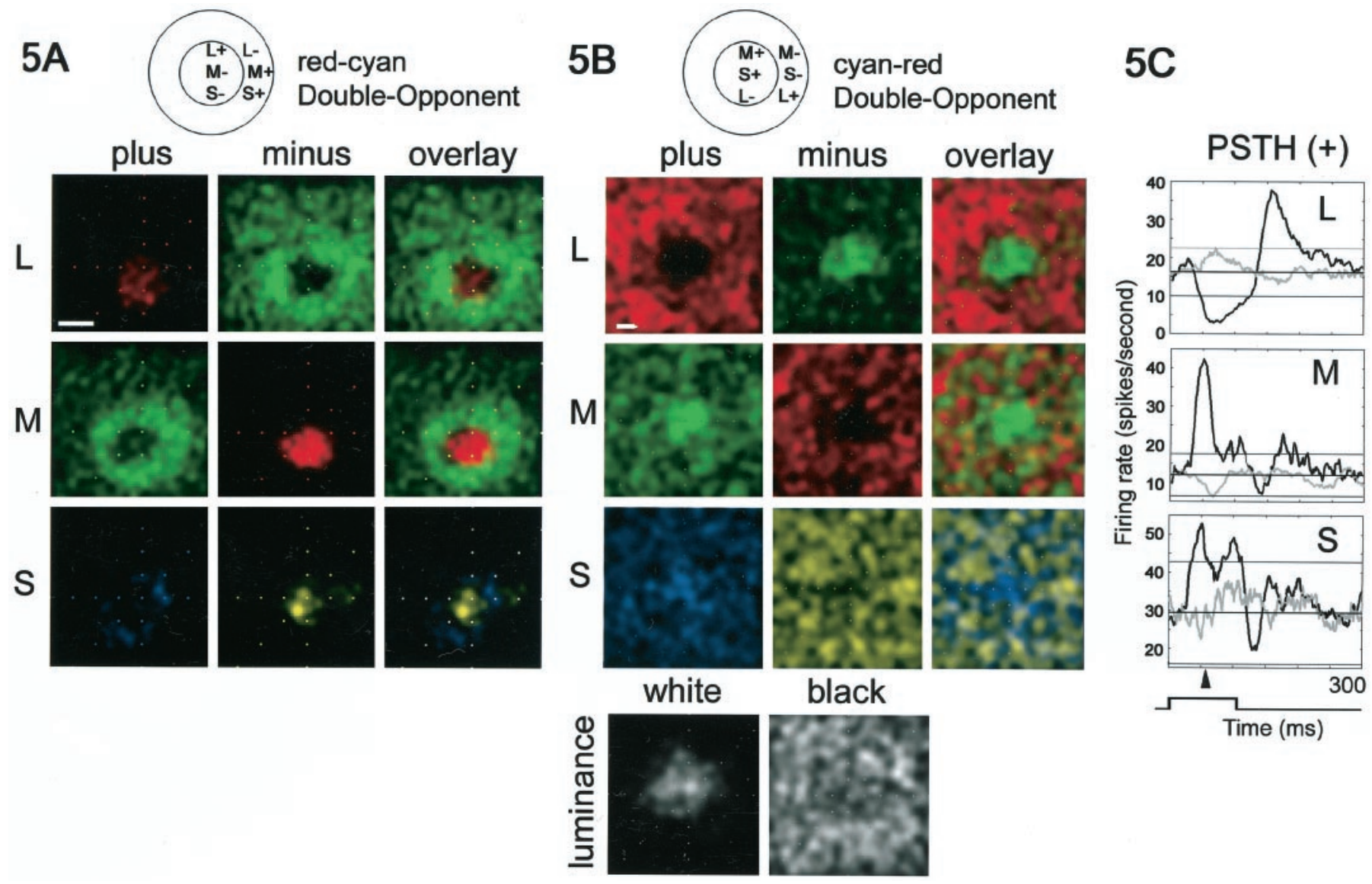

Figure 5. Response maps for a strongly Double-Opponent cell $(A)$ and a weakly Double-Opponent cell $(B)$. Conventions as in Figure 4. $A$, Peak firing rates (spikes per second) were as follows: L-plus, 53; L-minus, 37; M-plus, 55; M-minus, 71; S-plus, 10; S-minus, 54. $B$, Peak firing-rates (spikes per second) were as follows: L-plus, 23; L-minus, 43; M-plus, 41; M-minus, 12; S-plus, 53; S-minus, 37; white, 32; black, 22 . Both cells were $5^{\circ}$ peripheral; stimuli were $0.4 \times 0.4^{\circ}$. Scale bar (in $A$ and $B$ ), $0.5^{\circ}$. $C$, Responses were determined from the reverse correlation data by selecting segments of the spike train corresponding to presentations of plus stimuli in the center (black traces) and surround (gray traces) of the cell whose response maps are given in $B$. Stimulus duration was $100 \mathrm{msec}$ (indicated at bottom). The response maps in $B$ correspond to the response of a cell between 50 and 70 msec after the onset of the stimulus (arrowhead). One SD above and below the mean background firing rate is given for reference.

histograms and varied for each stimulus condition (Fig. 3A). Most cells were completely suppressed by either the L-plus or the M-plus stimuli (Fig. 3B). For the cell given in Figure $3 A$, for example, the M-plus stimulus might have been capable of reducing the firing of the cell even further but, because the activity of the cell cannot drop below zero spikes per second, one cannot measure the total extent of suppression, at least with extracellular recording. Because most cells showed a reduction to zero firing to one of the two screening stimuli (Fig. $3 B$ ), it is likely that the stimulus was capable of more suppression than could be measured directly. To find a more meaningful measure of suppression, I assumed that the suppression was equal in magnitude but opposite in sign to the excitation produced by the opposite contrast stimulus (Tolhurst and Dean, 1990; Ferster, 1994). For example, the suppression by M-plus would be equal, but opposite in sign, to the peak excitation by M-minus (Fig. 3A, asterisk).

I plotted the center and surround responses to $\mathrm{L}$ modulation and $\mathrm{M}$ modulation for all cells having the complete ensemble of maps (Fig. 9A,B). For the center response, all the red-on-center cells (open squares) fall into quadrant 4; the centers were excited by an increase in L-cone activity and suppressed by an increase in M-cone activity. The green-on-center cells ( filled circles) fall into quadrant 2; the centers were suppressed by an increase in L-cone activity and excited by an increase in M-cone activity. The dis- tribution of cells in quadrants 2 and 4 indicates that the centers of all cells were chromatically opponent (this is not surprising given that the cells were screened for this). The populations swap quadrants when their surround responses are plotted (Fig. 9B). This shows that the red-on-center cells were excited by M-plus and suppressed by L-plus in their surrounds, and the green-oncenter cells were excited by L-plus and suppressed by M-plus in their surrounds. That the cells swap quadrants indicates that the cells were both chromatically and spatially opponent and earns them the designation Double-Opponent. The strength of the centers could not be accurately predicted by the strength of the surrounds (Fig. 9C), although surrounds were generally weaker than the centers. The contribution of the surrounds to the responses of the cells may, however, be underestimated because this measure of surround strength does not account for the larger spatial extent of the surrounds.

The relationship of the response to $\mathrm{M}$ modulation versus $\mathrm{L}$ modulation has a slope of $-0.95\left(r^{2}=0.84\right)$ (Fig. 9A, Center) and $-0.98\left(r^{2}=0.53\right)$ (Fig. 9B, Surround). This shows that the cells responded equally well to L-plus modulation (a stimulus that looks bright red on a darker bluish-green background) and to M-minus modulation (a stimulus that looks dark bluish-red on a brighter green background). Similarly, the cells responded equally well to M-plus modulation (a stimulus that looks bright 
Figure 6. Comparison of response maps generated using high cone-contrast stimuli and low cone-contrast stimuli. $A$, Response maps for the red-on-center cell shown in Figure $5 A$ were generated using both high cone-contrast stimuli (top panels) and low cone-contrast stimuli (bottom panels). Only the maps for M-plus and M-minus are shown. The responses are color-coded with a linear color scale bar: black represents zero spikes per second, and the darkest red represents 90 spikes per second. All maps reflect responses after the same number of stimulus presentations. Scale bar, $0.5^{\circ} . B$, Difference maps between the minus and plus response maps. White represents no difference between the minus and plus maps. Note that the region surrounding the receptive field for the low cone-contrast stimulus is approximately white, reflecting the constant background activity between the plus and minus conditions. This is not the case for the high cone-contrast stimuli, which have different adapting backgrounds and therefore different background firing rates for the plus and minus conditions.

\section{$6 \mathrm{~A}$}
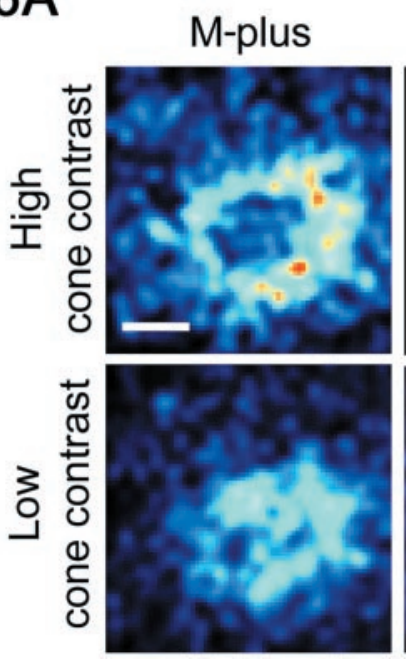

M-minus

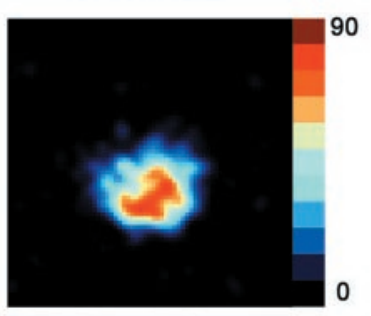

6B

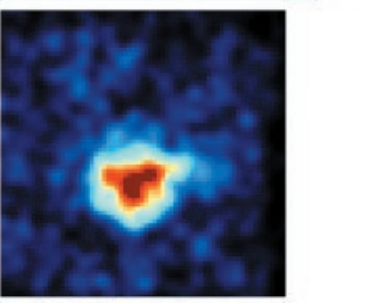

(plus-minus)

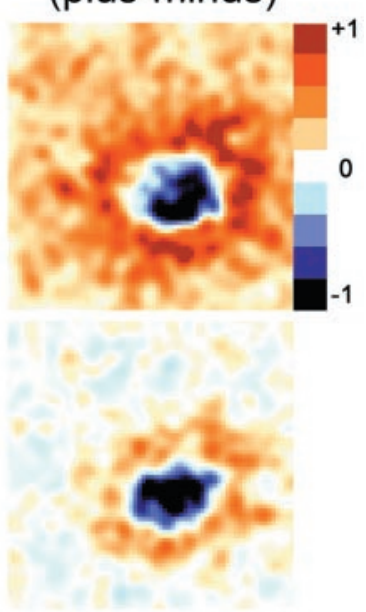

green on a bluish-red background) and to L-minus modulation (a stimulus that looks dark bluish-green on a bright red background). The cells were thus responding as well to a bright color as they were to a dark color. This luminance-invariant color response was true for both the red-on-center cells and the greenon-center cells (Fig. 9A). Such a comparison is possible because the L- and M-cone-isolating stimuli have nearly identical modulation indices (see Materials and Methods).

\section{Do red-green cells receive S-cone input?}

In addition to being modulated by the L- and the M-coneisolating stimuli, most red-green color cells (45 of 49, 92\%) were modulated by the S-cone-isolating stimulus (Fig. 9D). In most of these (42 of 45, 93\%), S-cone responses were elicited in the same spatial distribution and had the same sign as responses to M-coneisolating stimuli. These cells might tentatively be called red-cyan (cyan is green plus blue). The remaining three cells with significant S-cone input had S-cone input aligned with the L-cone input (Fig. 8). These might be green-magenta cells.

The similarity in $\mathrm{S}$ and $\mathrm{M}$ input raises the possibility that the $\mathrm{S}$-cone stimulus was not cone-isolating. Of course the fact that $\mathrm{M}$ and $\mathrm{S}$ responses are correlated (Fig. 9D) cannot be used by itself to assert that the S-cone responses are an artifact; if red-green cells receive S-cone input, then presumably it would be well balanced with the other cone inputs in the same way the $\mathrm{M}$ and $\mathrm{L}$ inputs are well balanced (Fig. 9A,B). The S-cone stimulus is probably not compromised because of macular pigmentation or lateral chromatic aberration (see Materials and Methods). In addition, several lines of evidence suggest that responses to the $\mathrm{S}$-cone stimulus are attributable to the activity of the S-cones and not to spillover stimulation of the M-cones.

(1) The response to the M stimulus did not perfectly predict the response to the $\mathrm{S}$ stimulus. Although there was a positive correlation between $\mathrm{M}$ and $\mathrm{S}$ modulation (slope of 0.75 ), $r^{2}=0.76$ (Fig. 9D). If the $\mathrm{S}$ stimulus was simply driving the red-green cells by modulating the M-cones (and not because the red-green cells received any $\mathrm{S}$-cone input), then one would expect a higher $r^{2}$ value.

(2) The $\mathrm{S}$ stimulus elicited a stronger response than the $\mathrm{M}$ stimulus in $33 \%$ ( 8 of 24 ) of the cells studied (e.g., Fig. 7). It is unlikely that a stimulus designed to modulate the S-cones would actually modulate the M-cones more than a stimulus designed to modulate the M-cones.

(3) The red-on-center cells frequently responded to the S-plus and S-minus stimuli in ways markedly different from the ways in which they responded to the M-plus and M-minus stimuli. This would not be expected if the S-cone stimulus was simply driving the cells through the M-cones. Whereas the centers of red-oncenter cells were suppressed and their surrounds excited by the M-plus stimulus, the S-plus stimulus often had little effect in center or surround (e.g., Fig. 4). The S-minus stimuli, however, often elicited a robust excitation from the center of these red-oncenter cells, a response that was often larger than that to any other stimulus (e.g., Fig. 4A). Similarly, whereas the centers of green-on-center cells were suppressed and their surrounds excited by the M-minus stimulus, the S-minus stimulus often produced little response. The S-plus stimulus, on the other hand, often elicited a robust response (e.g., Fig. 7).

(4) A few cells showed opposite responses to the S and M stimuli (Fig. 8).

(5) Cone-isolating stimuli that use the same cone fundamentals have been used to study red-green Type I cells in the lateral geniculate (Reid and Shapley, 1992). The S-cone stimulus in these cells was ineffective at driving the cells, and this has been used to argue that geniculate red-green Type I cells do not receive S-cone input. Presumably, if the S-cone stimulus significantly modulated the M-cones, then red-green Type I cells would have responded to it.

(6) Other investigators have obtained evidence for S-cone input in red-green cells (Gouras, 1970; Lennie et al., 1990; Cottaris and De Valois, 1998), and there is even some evidence that the $S$ input aligns with the M input. Vautin and Dow (1985) found that "green" cells were the only ones whose spectral tuning was not matched by the expected (i.e., M) cone fundamental. The spectral tuning included some shorter wavelengths. This could be reconciled by acknowledging the S-cone input to green-on cells and may also explain why some investigators found blue-green light better than green light for driving color cells (Livingstone and Hubel, 1984).

(7) Finally, despite the similarity in appearance between the S-minus and the M-plus stimuli (both look greenish), they elicited opposite responses in most cells.

The use in monkeys of cone fundamentals based on human 


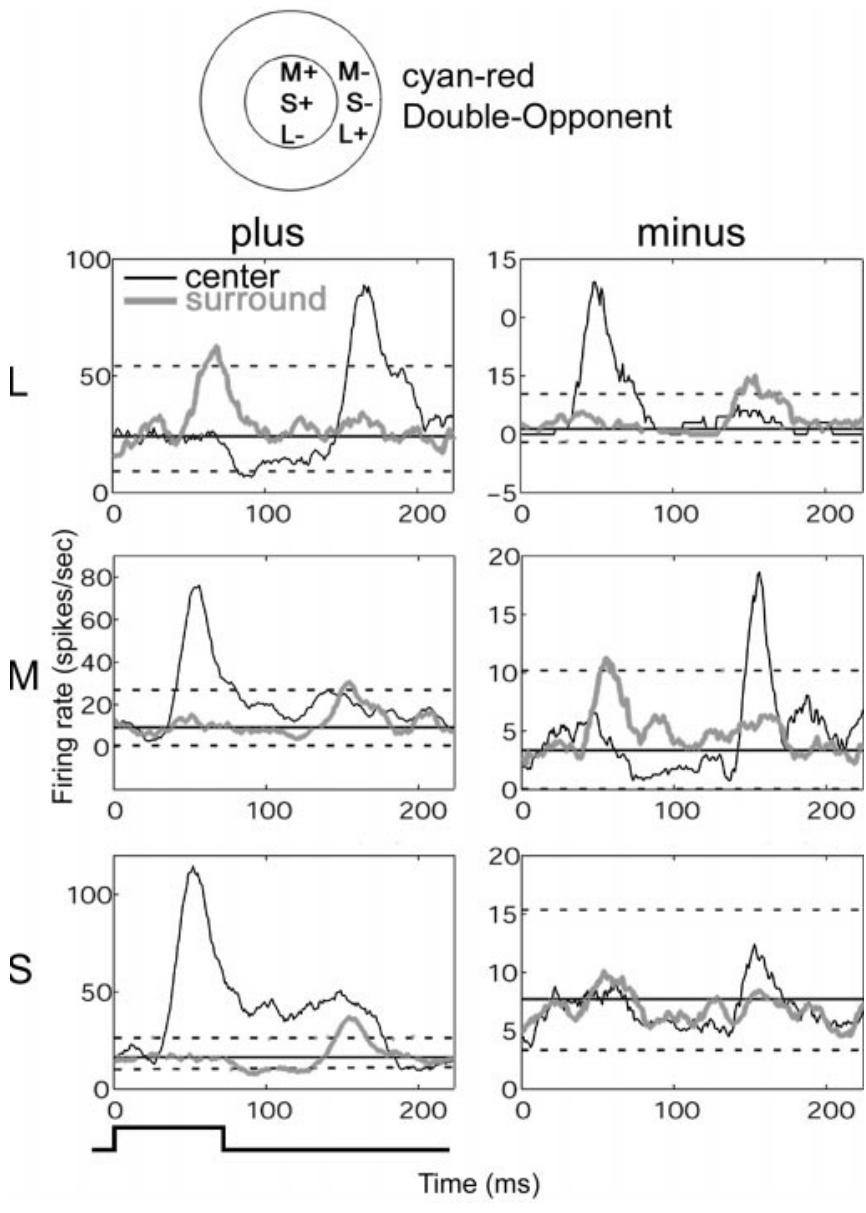

Figure 7. Temporal organization of a cyan-red Double-Opponent cell. Poststimulus time histograms corresponding to stimulation in the center (black traces) and surround (gray traces) for the plus stimuli (left plots) and minus stimuli (right plots) generated from the reverse correlation data (conventions as in Fig. 5C). A normalized mean firing rate was calculated based on the first $40 \mathrm{msec}$ (straight solid lines); one SD below and two above are plotted as reference (straight dotted lines). The cell was excited when an M-plus stimulus was presented in the center (middle left plot, black trace) and suppressed when an L-plus stimulus was presented in the center (top left plot, black trace). Inverse responses were obtained in the surround. The off-discharge after release of suppression is a useful indicator of the preceding suppression in situations in which the background activity was so low that suppression is not obvious (e.g., M-plus surround, middle left plot, gray trace). In addition to a strong surround response, this cell exhibited strong S-plus responses that coincided in space and sign with the M-plus responses; this is summarized in the diagram at top. Stimulus duration, $73 \mathrm{msec}$, indicated at the bottom left; stimulus size, $0.9 \times 0.9^{\circ}$. This cell was $3^{\circ}$ peripheral.

color matching functions is standard practice and seems justified (see beginning of Materials and Methods). However, because of the variability between and within species, it still remains possible that the use of these cone fundamentals is inappropriate and results in poor cone isolation. This is unfortunately a problem faced by almost all contemporary studies of monkey color physiology because almost all stimuli [both cone-isolating and DKL (Derrington et al., 1984)] use these fundamentals (Lennie et al., 1990; Reid and Shapley, 1992; Kiper et al., 1997; Cottaris and De Valois, 1998; Chichilnisky and Baylor, 1999; Seidemann et al., 1999).

Although the above discussion suggests that the S-cone input is real, it is important to note that red-green cells having no S-cone input might respond to an S-cone stimulus anyway. This is be- cause the S-cone stimulus might be subject to longitudinal (or axial) chromatic aberration and consequently might not be coneisolating (see Note concerning S-cone stimulus in Materials and Methods) (but see Cottaris et al., 2000). In fact, red-green cells having no S-cone input might be expected to respond (at least weakly) to the S-cone stimulus in a way predicted by the responses to the L-minus stimulus, and this is the case (L-minus responses overlap with $\mathrm{M}$-plus responses and therefore might underlie the positive correlation between S- and M-cone input) (Fig. 9D). Thus, the issue of S-cone input into most red-green cells seems unresolved and likely irresolvable using spatially structured stimuli and silent substitution. However, studies using full-field stimuli (in which longitudinal chromatic aberration is not a problem) suggest that at least some red-green cells receive significant S-cone input (Lennie et al., 1990). In the present study, I also found that a very large $\mathrm{S}$-cone stimulus elicited a robust response (data not shown). Moreover, several cells in the present study (8 of 24) (Figs. $3 A, 7$ ) gave responses to the $\mathrm{S}$-cone stimulus that were greater than the responses they gave to any other stimulus. Presumably, the S-cone input in at least these cells is genuine. Finally, it may be interesting to note that an alignment of responses to S- and M-cone-isolating stimuli might not be coincidence; S-cones seem to reside preferentially next to M-cones in a bed of abundant L-cones (Conway, 2000). This might suggest that development places S-cones next to $\mathrm{M}$-cones to serve as a retinal substrate for a red-cyan chromatic axis.

\section{Cone interactions}

In the final set of experiments, I designed cone-isolating stimuli that enabled me to stimulate two classes of cones simultaneously. This allowed me to test predictions of how the cone inputs are combined; the plots produced are called cone interaction maps. To present two cone-isolating stimuli simultaneously, it is necessary to present them on a constant adapting (gray) background (see beginning of Results).

Many reports indicate that color-selective cells are mainly unoriented (Livingstone and Hubel, 1984; Ts'o and Gilbert, 1988). I found this also to be so. The cells that did show some mild orientation preference [ 9 of 49 cells, class $\mathrm{B} / \mathrm{C}$ in the four point subjective scale, in which $\mathrm{A}$ is most tuned (Livingstone and Hubel, 1984)] reflected this preference in the asymmetric spatial distribution of their cone inputs (Fig. 10A). The orientation preference of these cells was usually only revealed using colored bars because the cells responded poorly to white bars (Fig. 10B). These mildly orientation-selective cells were useful in studying the cone interactions because the subregions could be conveniently stimulated with bars. The use of bars was important because it enabled more of the receptive field to be stimulated, thus partially overcoming the low cone contrast of the stimuli. The L-plus cone-isolating stimulus looked like a pastel red bar on a gray background, the M-plus looked pastel green on the same gray, and the S-plus looked pastel lavender on the same gray. An additional advantage of these stimuli is that they could be overlapped in a meaningful way; the overlap of L-plus and M-plus stimuli, for example, elicited a relative L-cone activity identical to that of the L-plus stimulus and an M-cone activity identical to that of the M-plus stimulus, leaving the S-cones unaffected. This stimulus looked yellowish.

I used the reverse correlation two-bar presentation technique (Ohzawa et al., 1997) with eye-position correction (Livingstone and Tsao, 1999) to generate a profile of the response of one cone against another (all plus stimuli). Pairs of bars of optimum ori- 
A
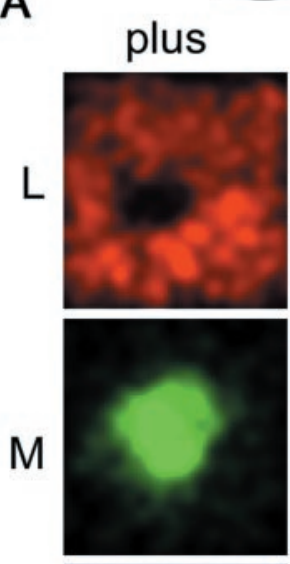

s
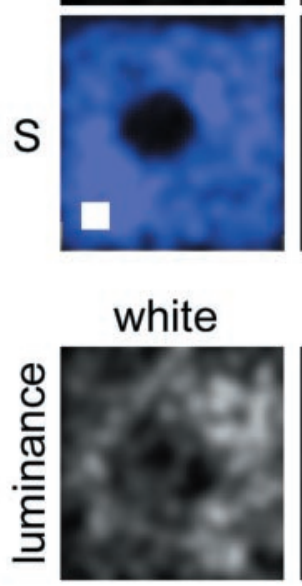

minus
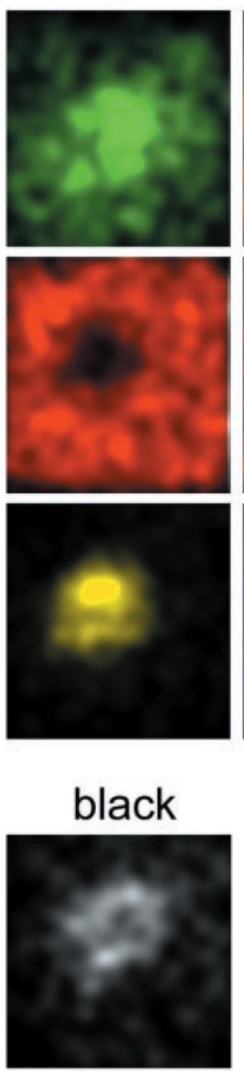

B
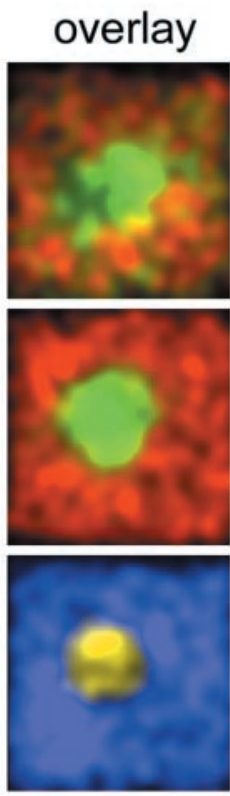

S
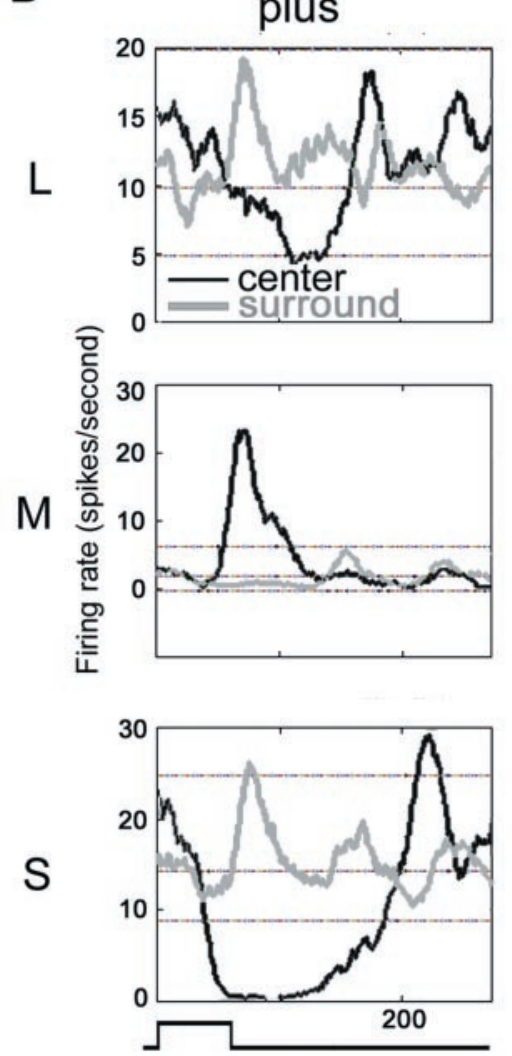

minus
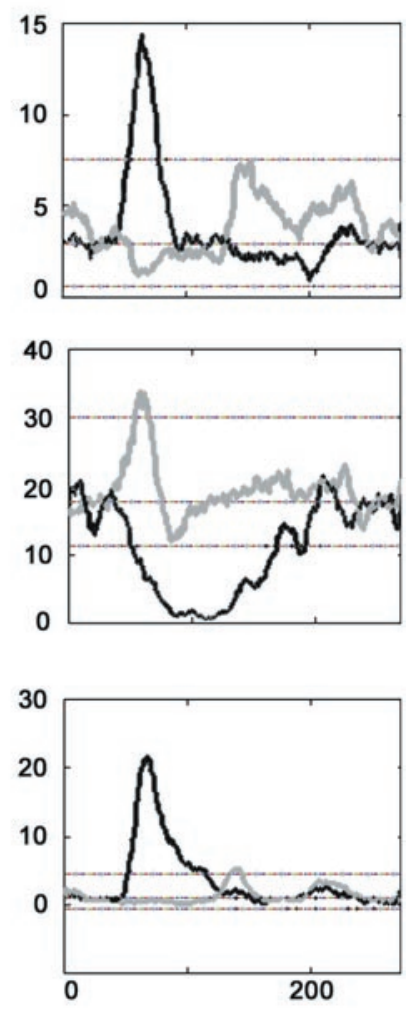

Time (ms)

Figure 8. Response maps and temporal organization for a green-magenta Double-Opponent cell. $A$, Response maps to the six stimuli conditions; conventions as in Figure 4. Stimulus size was $0.4 \times 0.4^{\circ}$, shown at the bottom left. Unlike the other cells shown, the S-cone input in this cell aligns in space and sign with the L-cone input, justifying a description of this cell as green-magenta (in which magenta is red plus blue). $B$, Temporal organization of the response of the cell whose spatial response maps are shown in $A$. Conventions as in Figure $5 C$. Center, black traces; surround, gray traces; plus stimuli, plots on the left; minus stimuli, plots on the right. One SD below and two above the mean firing rates are shown for reference. Stimulus duration is indicated at the bottom left.

entation were presented simultaneously at random locations along a line perpendicular to the orientation preference of the cell through the receptive field center. The response to simultaneous presentation of these two bars was then plotted in Cartesian coordinates in which at every point in the plot the cell response is given by a color code [which has nothing to do with the stimulus color; see the color scale bar (Fig. 10C, top panel)]. The ordinate represents the position of one of the bars; the abscissa represents the position of the other.

A representative interaction map for an oriented cell is shown in Figure $10 C$. The diagonal scale bar in Figure $10 A$ illustrates the line along which bars of optimum orientation were shifted; this is not the orientation of the bars used to stimulate the cell but rather the axis perpendicular to the orientation preference. The bars were $1.7 \times 0.3^{\circ}$ and had an orientation of $67^{\circ}$ counterclockwise from vertical. The scale bar in Figure $10 A$ is the ordinate and abscissa of the interaction plots (Fig. 10C). L-plus was mapped against M-plus (Fig. 10C, top panel), L-plus against S-plus (Fig. $10 C$, middle panel), and M-plus against S-plus (Fig. 10C, bottom panel). The yellow dotted $x=y$ diagonal (Fig. 10C) represents the locations throughout the receptive field at which the bars overlapped. Regions flanking this diagonal represent locations in which the bars were adjacent. In interpreting the interaction maps, it is useful to relate the response of the cell to the position that the pair of bars would have occupied in the receptive field given in Figure $10 \mathrm{~A}$. For example, this cell was excited by presentation of an M-plus bar in the region between 0.5 and $1^{\circ}$, which is represented in Figure 10, both $A$ and $C$, top panel, $y$-axis.

The response of the cell depended not only on the location of the presentation of one bar but also on the location of presentation of the other. For example, the excitation produced when the L-plus bar was presented in the L-plus-on subregion was cancelled when the M-plus bar overlapped the L-plus bar [Cartesian coordinates of $(1.25,1.25)$ in Figure $10 C$, top panel]. Likewise, the excitation produced when the M-plus bar was presented to the M-plus-on subregion was cancelled by an overlapping L-plus bar [Cartesian coordinates of $(0.75,0.75)$ in Fig. $10 C$, top panel]. This mutual suppression is reflected in the lack of response across the 

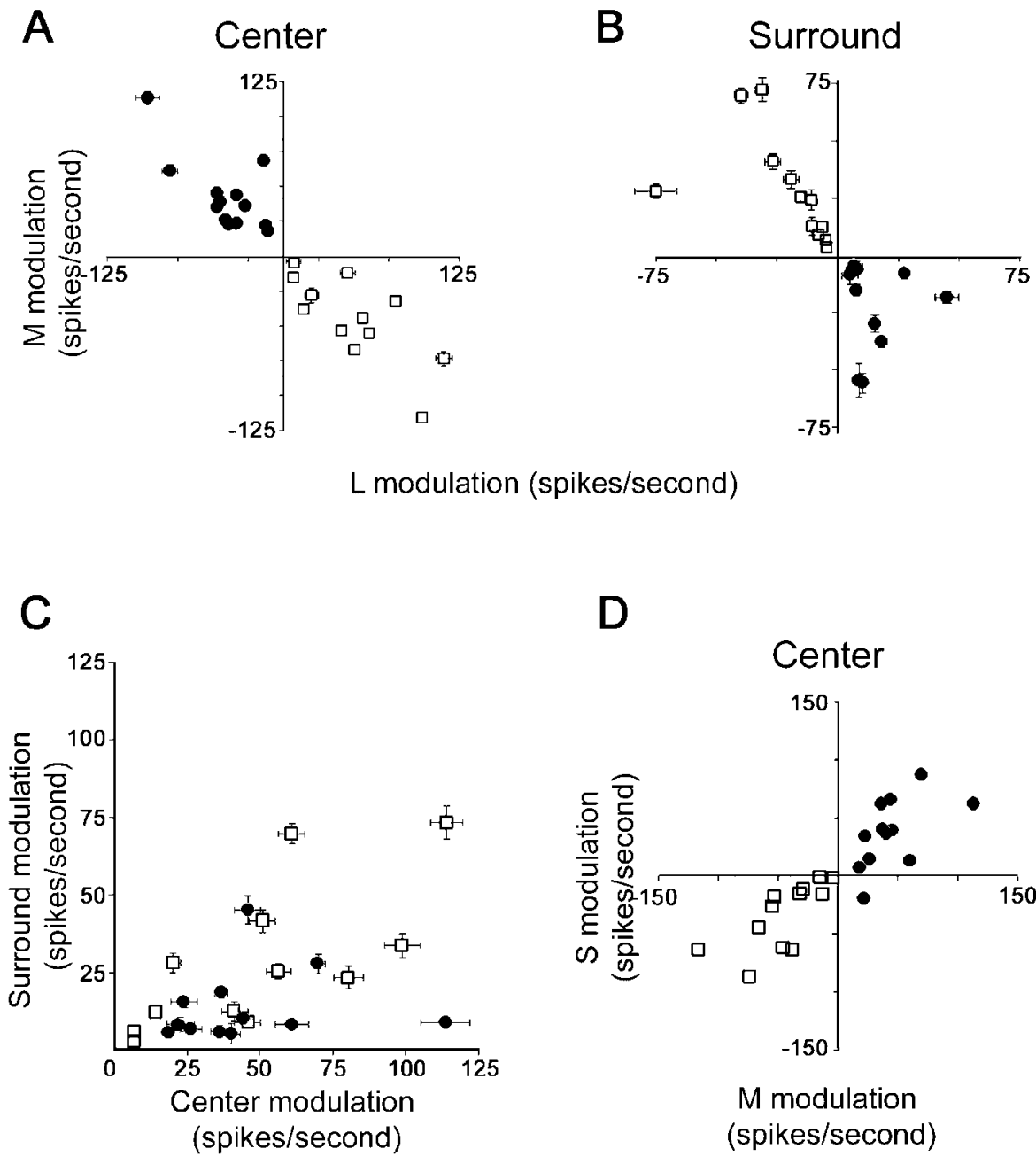

Figure 9. Quantification of cone inputs to cortical color cells. $A$, Responses were determined from the reverse correlation data by selecting segments of the spike train corresponding to stimulus presentations in the center. The stimuli often reduced the firing of the cells to zero spikes per second, making it impossible to directly measure the full extent of the suppression. To find a more meaningful measure of suppression (rather than reduction of background), I assumed that the suppression was equal in magnitude but opposite in sign to the excitation produced by the opposite contrast stimulus (see Results). For example, for the red-on-center cell shown in Figure 3A, the suppression by the M-plus stimulus would be equal, but opposite in sign, to the excitation by the M-minus stimulus (asterisk in Fig. 3 ). The responses of the cells to M modulation (ordinate) is plotted against the response to L modulation (abscissa). All green-on-center cells ( filled circles) fall in quadrant 2 , whereas all red-on-center cells (open squares) fall in quadrant 4 , showing that the centers were chromatically opponent. $B$, Surround responses were extracted from the reverse correlation data, as in $A$. The green-on-center cells and the red-on-center cells swap quadrants. This shows that the chromatic opponency of the surrounds of both populations of cells was opposite that of their centers. $C$, Surround responses were generally weaker than center responses. For greenon-center cells ( filled circles), the L-plus surround response is plotted against the M-plus center response. For red-on-center cells (open squares), the M-plus surround response is plotted against the L-plus center response. $D$, Red-green cells were often modulated by the S-cone-isolating stimulus. The response to presentation of the S-coneisolating stimulus in the center of the receptive field (ordinate) is plotted against the response the M-cone-isolating stimulus (abscissa). In all plots, the average background activity (see Fig. 3) was subtracted from the peak responses. portion of the $x=y$ diagonal that passes through both subregions (from 0.5 to $1.5^{\circ}$ ) (Fig. 10C, top panel). In addition, the response to simultaneous presentation of L-plus bars in the L-plus-on subregion and M-plus bars in the M-plus-on subregion was greater than the response to presentation of either bar alone [Cartesian coordinates of $(1.25,0.75)$ in Fig. $10 C$, top panel]. Likewise, S-plus bars adjacent to L-plus bars (Fig. 10C, middle panel) and M-plus bars on top of S-plus bars (Fig. 10C, bottom panel) resulted in increased firing. This is summarized by the poststimulus time histograms (Fig. 10D).

The cone interactions for a second cell are shown in Figure $10 E$. A diagram of the spatial organization of the receptive field (Fig. $10 E$, top panel) indicates the $\mathrm{M} / \mathrm{S}$-plus region at $0.25^{\circ}$ and the L-plus-on subregion at $0.5^{\circ}$ along the stimulus range. This stimulus range forms the axes of the interaction plots (Fig. 10E). As for the cell shown in Figure 10C, the response to simultaneous stimulation of both subregions (e.g., using L-plus bars in the L-plus-on subregion and M-plus bars in the M-plus-on subregion [Fig. 10E, top panel, coordinates of $(0.5,0.25)]$ ) was greater than the response to stimulation of a single subregion (summarized in Fig. $10 F$ ). Cone interactions were tested for seven cells. In some cells, the peak response to simultaneous stimulation of both subregions was predicted by the sum of the peak responses to separate stimulation of each subregion (Fig. 10D), and in others, the response to simultaneous stimulation was greater (Fig. 10F). The facilitated response, or expansive nonlinearity, of some of the cells (Fig. 10F) is consistent with a simple thresholding operation. Additional analysis of a greater sample of cells will be necessary to determine what fraction of cells respond to simultaneous stimulation in a linear way and what fraction of cells respond with an expansive nonlinearity.

\section{DISCUSSION}

\section{Color constancy and Double-Opponent cells}

The paradox of color perception is this: despite varying illumination conditions, the colors we assign to objects are remarkably constant. A red apple, for example, looks red under a blue sky, a cloudy sky, and a fluorescent light, despite the fact that the spectral distribution of light reflected from the apple are grossly different under each condition. The present study was undertaken because, although it has been shown that Double-Opponent cells could underlie this color constancy (see introductory remarks), the existence of Double-Opponent cells in the primate has been disputed.

The spatial structure of color cell receptive fields has typically been studied with simple colored spots and annuli (Michael, 1978; Livingstone and Hubel, 1984; Ts'o and Gilbert, 1988). These stimuli make arbitrary assumptions about the structure of the receptive fields, which can be problematic; in at least one study, the annuli used to stimulate the surrounds likely encroached on the centers (Ts'o and Gilbert, 1988, their Fig. 3). Furthermore, these stimuli are not cone-isolating, so the cone inputs can only be 
A
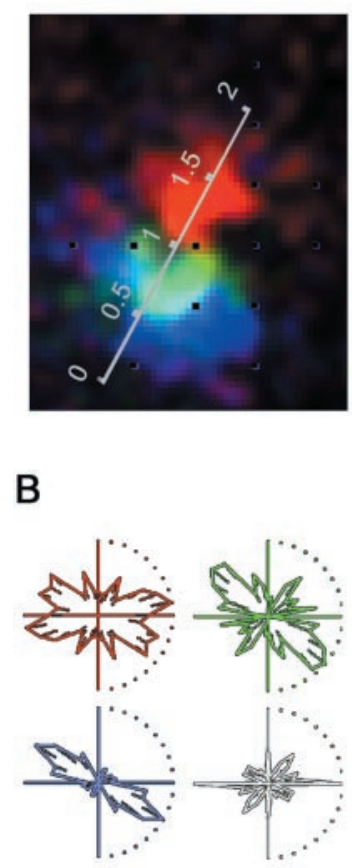

C
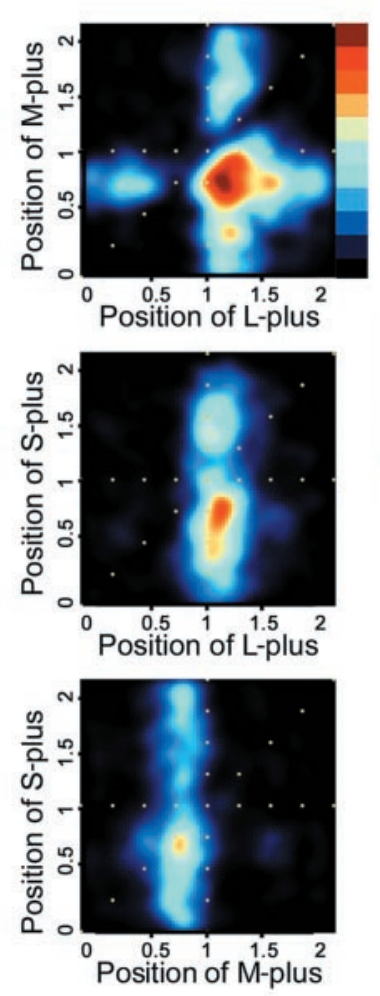

D
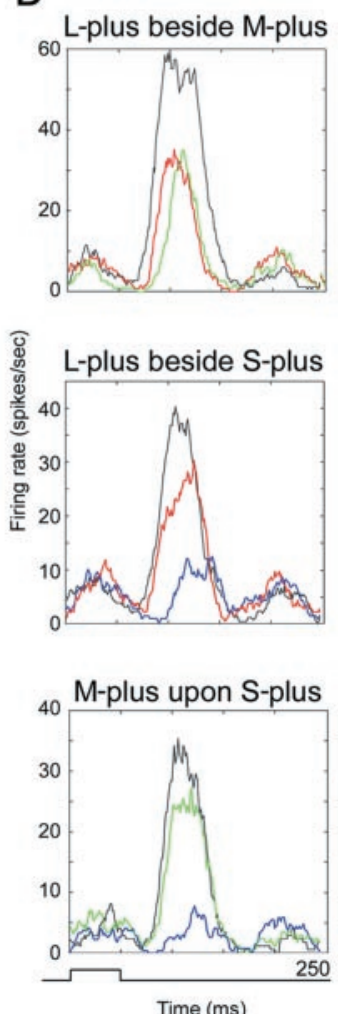
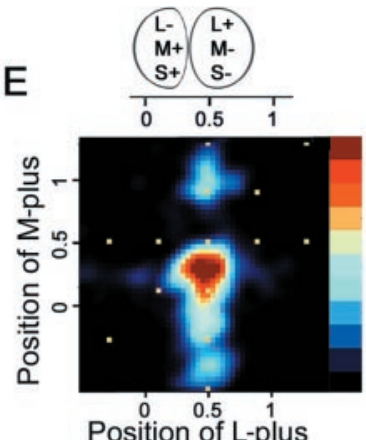

$\mathrm{F}$
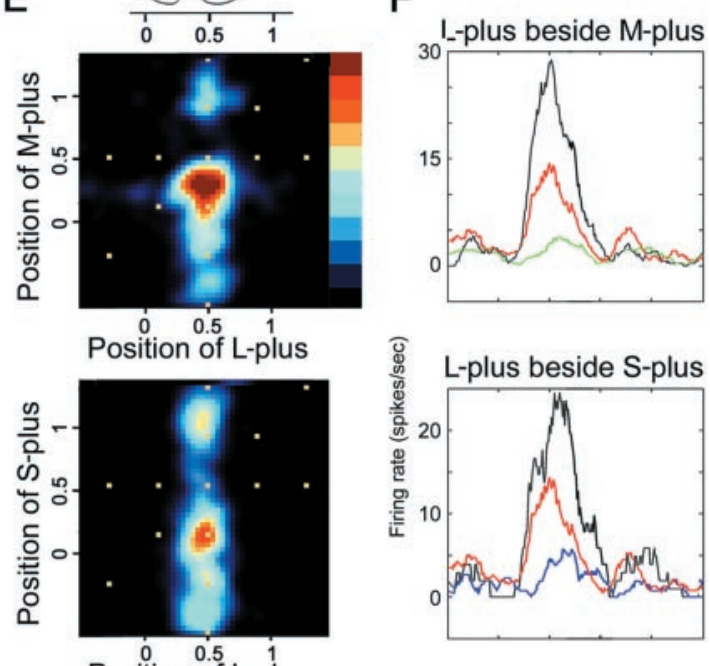

Position of L-plus

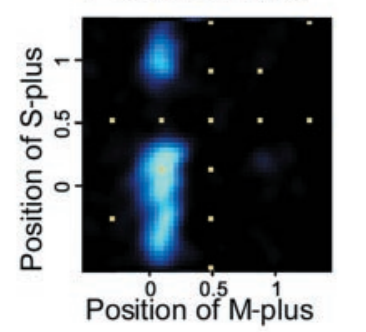

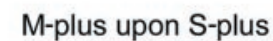

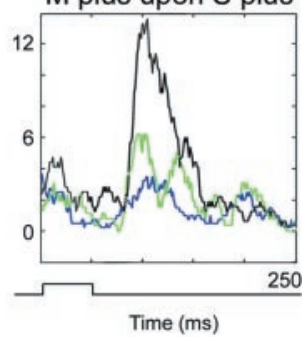

Figure 10. Interaction between the cone inputs of two oriented Double-Opponent cells. $A$, Reverse correlation map for the three plus stimuli for one cell; conventions as in Figure 4. The scale bar (in degrees) is placed perpendicular to the orientation preference of the cell. The M-plus response is between 0.5 and $1^{\circ}$, and the L-plus response is between 1 and $1.5^{\circ}$. Stimulus size, $0.3 \times 0.3^{\circ}$. B, Orientation tuning was generated using flashed oriented bars of cone-isolating stimuli and white. The cell responded poorly to white (white plot). The orientation tuning to L-plus bars (red plot), M-plus bars ( green plot), and S-plus bars (blue plot) is reflected in the orientation of the subregions of the response map shown in $A$. $C$, Responses to simultaneously presented pairs of optimally oriented cone-isolating bars (see Cone interactions in Results). Cell response is represented by the graded color scale, with black being 0 and dark red being 65 spikes per second. The axes of the plots are the same as the scale bar in $A$. Hence, in the top panel of $C$, the L-plus response is between 1 and $1.5^{\circ}$, and the M-plus response is between 0.5 and $1^{\circ}$. The $x=y$ diagonal denoted by yellow dots represents the position across the receptive field at which the bars overlapped. The response is decreased along this diagonal for the L-plus versus M-plus plot (top), similarly for the L-plus versus S-plus plot (middle), but the response is increased along this diagonal for the M-plus versus S-plus plot (bottom). As one would predict based on the response maps shown in $A$, the response is maximal when L-plus bars are placed adjacent to M-plus bars. This is indicated by the dark red in the top plot at the coordinates $(1.25,0.75)$. D . PSTHs corresponding to the peak responses in C. Black lines are the PSTHs to optimally placed pairs of bars; L-plus and M-plus bars are adjacent to each other (top panel), L-plus and S-plus bars are adjacent to each other (middle panel), and M-plus and S-plus bars are superimposed (bottom panel). Colored lines represent the response of the cell to the optimal placement of a single bar: L-plus, red lines; M-plus, green lines; S-plus, blue lines. Stimuli were presented for $48 \mathrm{msec}$, shown at the bottom. This cell was $5^{\circ}$ peripheral. E, Interaction maps for a second cell. The stimulus range (in degrees) forms the axes of the interaction plots and is also indicated below the diagram of the spatial organization of the receptive field (above top panel). Along the stimulus range, the M/S-plus-on subregion is $\sim 0.25^{\circ}$, and the L-plus-on subregion is $\sim 0.5^{\circ}$. The color scale bar (top panel) indicates the cell response; peak response (dark red) is 30 spikes per second. $F$, PSTHs corresponding to the peak responses in $E$; conventions as in $D$, above. This cell was $4^{\circ}$ peripheral. Stimulus size, $0.75^{\circ} \times 0.2^{\circ}$.

inferred. To describe the cone inputs, some have used DKL stimuli (Derrington et al., 1984; Lennie et al., 1990; Cottaris and De Valois, 1998). These stimuli modulate between two states, simultaneously increasing the activity of one cone class while decreasing the activity of a second. Unfortunately, only full-field versions of these stimuli have been used, and these would have confounded the responses of center and surround making it impossible to describe Double-Opponent cells. Moreover, DKL stimuli make it impossible to ascribe the response of a cell to the increase in activity of one cone class versus the decrease in activity of the second cone class because both happen simultaneously.

In the present study, single spots of cone-isolating stimuli were used to map V-1 color cells. The combination of these stimuli, alert animals, and an eye-position-corrected reverse correlation technique enabled the first direct assessment of the spatial structure of the receptive fields of V-1 color cells. Most V-1 color cells were shown to be Double-Opponent. There was no evidence that these cells are modified Type II. The surround strengths varied among cells, and it will be interesting to see what implications this has on the potential for Double-Opponent cells to perform illumination-independent responses. Regardless, these cells seem well suited to detecting color boundaries.

\section{The cortical chromatic axes}

It has been proposed that parvocellular geniculate cells, the majority of which are excited by L-cones and suppressed by M-cones or vice versa (Wiesel and Hubel, 1966; Derrington et al., 1984; Reid and Shapley, 1992), provide a substrate for a redgreen chromatic axis. This axis is thought to work with a blue- 


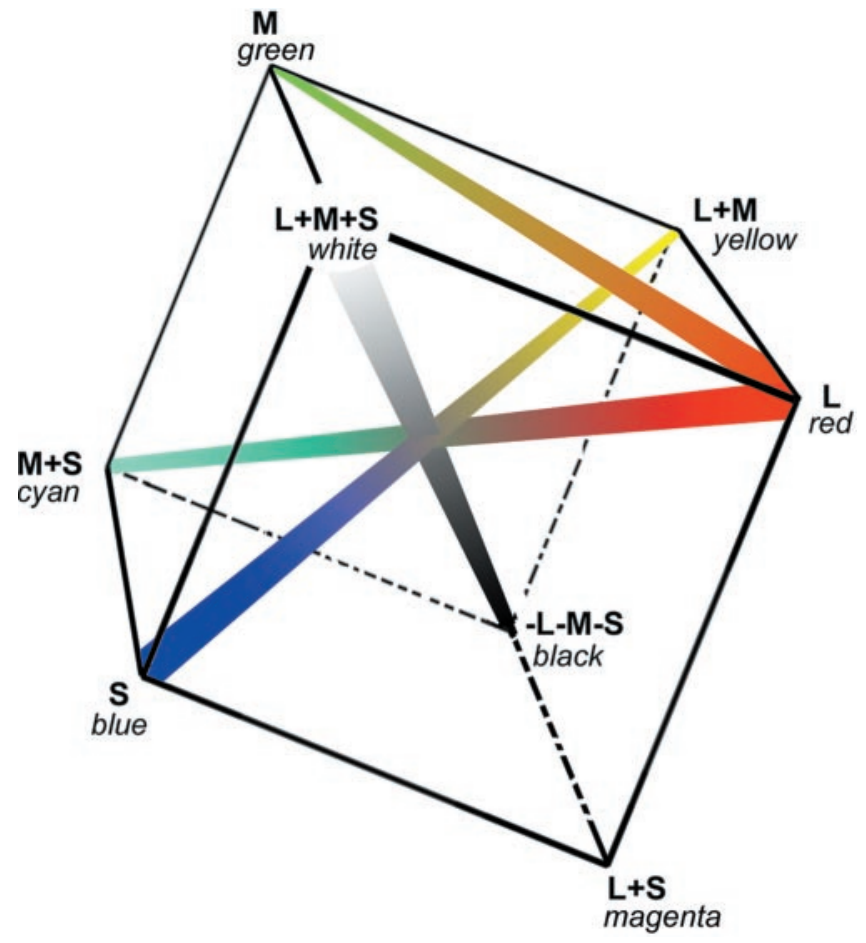

Figure 11. The results presented here suggest that the cortex exhibits a single red-green axis: the responses of red-green cells to an L-coneisolating stimulus are well predicted by their responses to an M-coneisolating stimulus (Fig. 9A,B). In the cortex, this red-green axis is presumably accompanied by a blue-yellow axis $[\mathrm{S}$ vs $(\mathrm{M}+\mathrm{L})]$ and a luminance axis (see Discussion). These three axes are sufficient to describe all of color space, represented here as a cube. In the present study, the majority of $\mathrm{L}$ versus $\mathrm{M}$ cells responded to an S-cone stimulus, and these responses aligned in space and sign with responses to the M-cone stimulus (Fig. 9D). If these responses reflect a genuine $\mathrm{S}$-cone input (and not an artifact of longitudinal chromatic aberration; see Note concerning S-cone stimuli in Materials and Methods), then these cells would be better described as $\mathrm{L}$ versus $1 / 2(\mathrm{M}+\mathrm{S})$, or red-cyan. The color names provide a useful mnemonic and seem justified. A stimulus that selectively increases the activity of M- and S-cones appears cyan; similarly, one that increases the activity of the L-cones appears red. $S$, Blue-violet; $L+M$, yellow.

yellow axis (Dacey and Lee, 1994) and a black-white axis to represent color space. The situation is not so simple in V-1 because distinct chromatic axes are not thought to exist (Lennie et al., 1990). Rather, cortical cells are thought to be tuned to many different colors (Lennie et al., 1990; Cottaris and De Valois, 1998). In fact, it has been argued that single cortical cells multiplex color selectivity and other visual attributes, including orientation selectivity (Lennie, 2000). The majority of cortical cells are orientation-selective; moreover, the optimal color of a stimulus will be different for each cell because the strength of the input from each cone class varies among cells (Lennie et al., 1990; Cottaris and De Valois, 1998). However, this "color selectivity" does not imply that these cells are responsible for color perception; the different weights of the cone inputs could reflect the fact that cortical cells are sampling a relatively small number of cones from a patchy cone mosaic. It seems more likely that the cortical color-coding cells are the relatively rare cells that show explicit opponency between cone classes. After all, such opponency is the hallmark of color perception (Hering, 1964). Thus, in the present report, I only studied cells that showed opponency between cone classes. (I restricted my study to L vs M cells, i.e., red-green cells.)
A
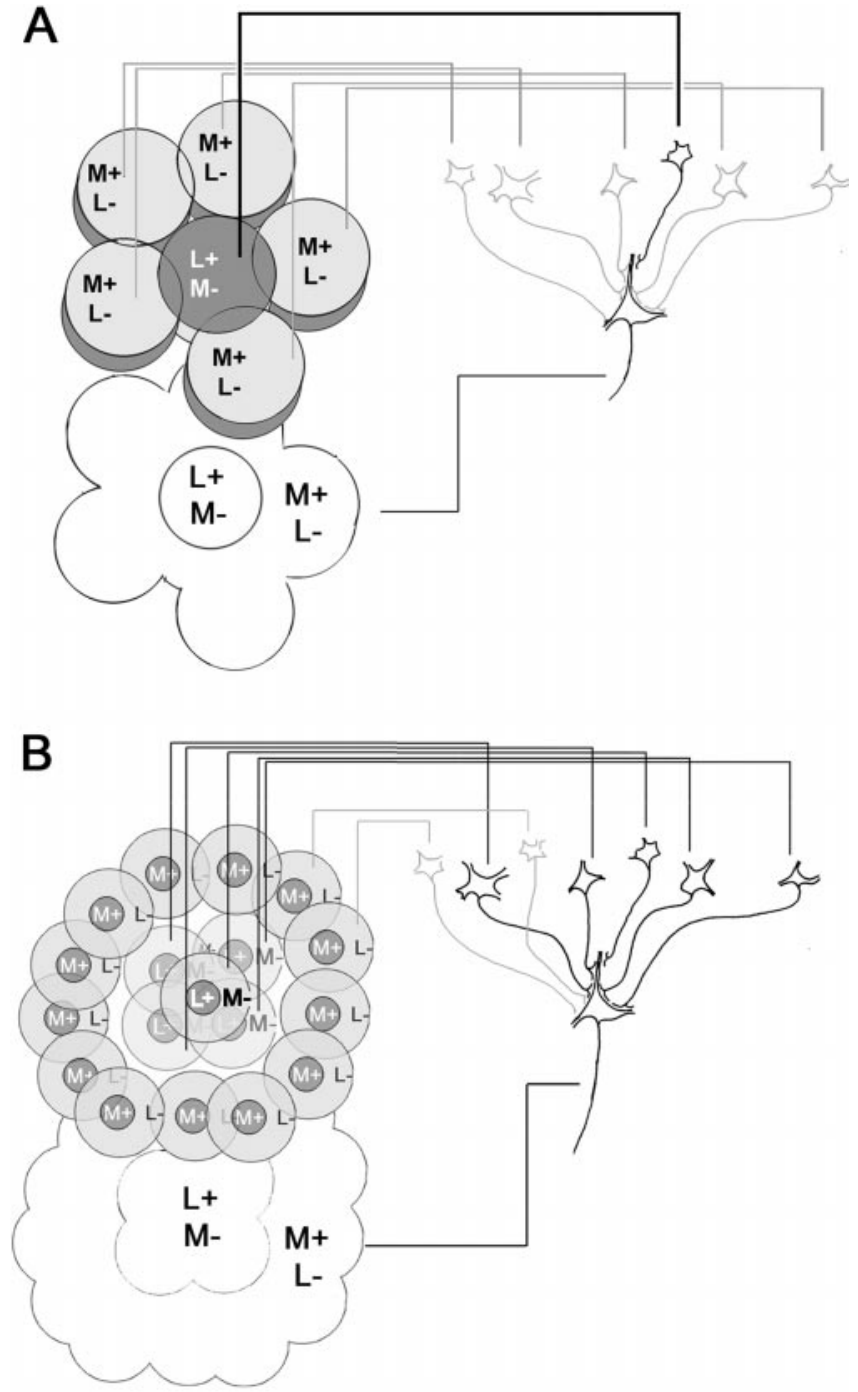

Figure 12. Models describing the hypothesized inputs into a DoubleOpponent cell. $A$, One red-on/green-off Type II cell feeds the center of the Double-Opponent cell. The surround is fed by Type II cells of opposite configuration, green-on/red-off (shown in gray) (adapted from Michael, 1978). Although early studies suggest the existence of red-green Type II cells in the LGN, subsequent investigators have not found them. Thus, although LGN Type II cells may be involved in forming blueyellow cortical Double-Opponent cells, an alternative model is required for the formation of cortical red-green Double-Opponent cells. For example, $B$, a group of parvocellular LGN Type I cells whose receptive field centers are dominated by the same cone class (in this case L), could feed the center, whereas the surround could be fed by Type I cells of the opposite configuration ( 2 cells are shown in gray). A cortical red-green Type II cell would result if the surround were insignificant.

Red-on-center cells were suppressed by M-cone-isolating stimuli to the same extent that they were excited by L-cone-isolating stimuli; similarly, green-on-center cells were suppressed by L-cone-isolating stimuli as well as they were excited by M-coneisolating stimuli (Fig. 9A). This shows that these cells are concerned with the color and not the luminance of the stimulus; red-on-center cells, for example, responded equally well to a stimulus that appeared bright red (L-plus) and to a stimulus that appeared dark red (M-minus). Moreover, the fixed ratio of $\mathrm{L}$ - and M-cone inputs (Fig. 9A,B) argues that these cells are encoding a single chromatic axis. This axis would presumably be complemented by the well documented $\mathrm{S}$ versus $(\mathrm{L}+\mathrm{M})$ (or blue- 
yellow) axis (Dacey and Lee, 1994) and a luminance (or blackwhite) axis. These three axes are sufficient to describe all of color space (Fig. 11). Specific hues are likely encoded by the cumulative activity of cells representing these three axes. Thus, in the same way a specific hue on a computer monitor requires values for all three phosphors (R, G, or B), the perception of specific hues would require the activity of all three chromatic axes. Moreover, only three cells (one for each chromatic axis) would be required for every receptive field location. This seems an efficient means of encoding color and is consistent with the number of color cells observed here $[\sim 10 \%$ of cortical cells were red-green; seven times fewer cortical cells are blue-yellow (Livingstone and Hubel, 1984)].

Cortical red-green cells usually responded to the S-cone stimulus (Fig. 9D). This response might be the result of a compromise of cone isolation attributed to chromatic aberration (see Results and Note concerning S-cone input in Materials and Methods), but it also might reflect genuine $\mathrm{S}$-cone input. If genuine, the cortical red-green axis might be better described as red-cyan [or L vs $1 / 2(M+S)$, as suggested by Fig. 9] because responses to the $S$ stimulus usually aligned in space and sign with those to the $\mathrm{M}$ stimulus (in $93 \%$ of cells). A red-cyan axis might be advantageous because it (and the blue-yellow axis) would be silent to shades of gray (Fig. 11). That is, the intersection of the null planes of the two axes will be achromatic. This is not true for the conventional red-green ( $\mathrm{L}$ vs $\mathrm{M}$ ) and blue-yellow axes.

If the response to the $\mathrm{S}$-cone stimulus reflects an $\mathrm{S}$ input, it is surprising that it aligns with the $\mathrm{M}$ input and not the $\mathrm{L}$ input. Long-wavelength light activating the L-cones appears reddish, but so does very short-wavelength light activating the S-cones (Ingling, 1977). It might seem logical that the cells responsible for the perception of "red" would pool inputs from S and L cones. However, color perception is likely performed by the cumulative activity of the three chromatic axes (and subsequent areas V4 or V8) and not single V-1 cells. Alternatively, the relatively rare M versus $(\mathrm{L}+\mathrm{S})$ cells could mediate the redness of shortwavelength light (Fig. 8).

\section{The wiring of Double-Opponent cells}

Most parvocellular geniculate Type I cells are color opponent (De Valois et al., 1966; Wiesel and Hubel, 1966; Reid and Shapley, 1992) (Fig. 1A), and one might assume they supply cortical Double-Opponent cells. However, Type I cells might be color opponent as a byproduct of their high spatial resolution [their receptive field centers are often fed by single cones (Calkins and Sterling, 1999)], and consequently the involvement of Type I cells in color perception (and in wiring Double-Opponent cells) might be an unjustified assumption. For this reason, Type II cells [the receptive fields of which comprise many cones (Wiesel and Hubel, 1966; Chichilnisky and Baylor, 1999)] may be the dominant input into cortical color cells (Hubel and Livingstone, 1990; Rodieck, 1991). There is a close match between the size of Type II cell receptive fields and the centers of cortical DoubleOpponent cells, lending support to this hypothesis. Moreover, the koniocellular layers, which contain Type II cells (Livingstone and Hubel, 1984; Martin et al., 1997), project to the cytochrome oxidase-rich blobs (Livingstone and Hubel, 1982; Diamond et al., 1985), regions that are rich in color cells (Livingstone and Hubel, 1984; Ts'o and Gilbert, 1988).

A single Type II cell would feed the center of a DoubleOpponent cell, whereas several Type II cells of opposite chromatic tuning would feed the surround (Fig. 12A) (Michael, 1978).
A major shortfall of this hypothesis, however, is that geniculate red-green Type II cells have not been documented [besides the original assertion of their existence (Wiesel and Hubel, 1966; Livingstone and Hubel, 1984)]. Thus, parvocellular Type I cells might be the only available substrate for cortical red-green Double-Opponent cells (Fig. 12B). In this model, the center could be formed by pooling geniculate Type I cells of similar chromatic tuning; the surround could be formed by intracortical lateral connections known to exist between patches of cortex that are rich in color cells (Livingstone and Hubel, 1984). Thus, Michael's model (Fig. 12A) might be modified slightly such that the substrate for Double-Opponent cells is cortical (and not geniculate) red-green Type II cells. That geniculate Type I cells are the substrate for cortical red-green cells is supported by two findings. First, the morphology of one color cell showed that it arborized heavily in layer 4C $\beta$ (Anderson et al., 1993). [Layer $4 \mathrm{C} \beta$ is the cortical target of the parvocellular lateral geniculate and itself is thought to contain Type I cells (Livingstone and Hubel, 1984).] Second, Type I cells have well balanced L versus $\mathrm{M}$ inputs (Derrington et al., 1984), as do cortical red-green cells (Fig. 9A).

In summary, most $\mathrm{V}-1$ cells probably do not multiplex multiple visual attributes (e.g., form and color). The cells studied here, for example, have large receptive fields and lack sharp orientation selectivity, making them an unlikely substrate for high-resolution form perception. Instead, they have receptive fields that are both spatially and chromatically opponent, making them well suited to subserve color perception. The large receptive field sizes of Double-Opponent cells might limit the spatial resolution they could encode. Indeed, this is consistent with our lower acuity for images in which color is the only cue (Liebmann, 1926; Granger and Heurtley, 1973; De Valois and Switkes, 1983; Mullen, 1985; Livingstone and Hubel, 1987) (but see Cavonius and Schumacher, 1966). Finally, the fixed ratio of $L$ and $M$ input that redgreen Double-Opponent cells receive suggests that these cells establish a single chromatic axis which, in conjunction with a blue-yellow and a black-white axis, is sufficient to describe all of color space.

\section{REFERENCES}

Albers J (1963) Interaction of color, pp 20-21. New Haven, CT: Yale UP.

Anderson JC, Martin KA, Whitteridge D (1993) Form, function, and intracortical projections of neurons in the striate cortex of the monkey Macacus nemestrinus. Cereb Cortex 3:412-420.

Baylor DA, Nunn BJ, Schnapf JL (1987) Spectral sensitivity of cones of the monkey Macaca fascicularis. J Physiol (Lond) 390:145-160.

Calkins DJ, Sterling P (1999) Evidence that circuits for spatial and color vision segregate at the first retinal synapse. Neuron 24:313-321.

Cavonius CR, Schumacher AW (1966) Human visual acuity measured with colored test objects. Science 152:1276-1277.

Chichilnisky EJ, Baylor DA (1999) Receptive-field microstructure of blue-yellow ganglion cells in primate retina. Nat Neurosci 2:889-893.

Conway BR (2000) Spatial organization of cone contributions to color cells in alert macaque primary visual cortex. Soc Neurosci Abstr 26:54.14.

Cottaris NP, De Valois RL (1998) Temporal dynamics of chromatic tuning in macaque primary visual cortex. Nature 395:896-900.

Cottaris NP, Elfar SD, De Valois RL (2000) Strong S-cone inputs to macaque V1 simple cell spatio-temporal chromatic receptive fields corrected for axial chromatic aberration. Soc Neurosci Abstr 26:54.11.

Dacey DM, Lee BB (1994) The "blue-on" opponent pathway in primate retina originates from a distinct bistratified ganglion cell type. Nature 367:731-735.

Daw N (1968) Goldfish retina: organization for simultaneous color contrast. Science 158:942-944.

Daw NW (1972) Color-coded cells in goldfish, cat, and rhesus monkey. Invest Ophthalmol 11:411-417.

De Monasterio FM (1978) Properties of ganglion cells with atypical 
receptive-field organization in retina of macaques. J Neurophysiol 41:1435-1449.

De Monasterio FM, Gouras P (1975) Functional properties of ganglion cells of the rhesus monkey retina. J Physiol (Lond) 251:167-195.

De Valois KK, Switkes E (1983) Simultaneous masking interactions between chromatic and luminance gratings. J Opt Soc Am 73:11-18.

De Valois RL, Abramov I, Jacobs GH (1966) Analysis of response patterns of LGN cells. J Opt Soc Am 56:966-977.

De Valois RL, Morgan HC, Polson MC, Mead WR, Hull EM (1974) Psychophysical studies of monkey vision. I. Macaque luminosity and color vision tests. Vision Res 14:53-67.

Derrington AM, Krauskopf J, Lennie P (1984) Chromatic mechanisms in lateral geniculate nucleus of macaque. J Physiol (Lond) 357:241-265.

Diamond IT, Conley M, Itoh K, Fitzpatrick D (1985) Laminar organization of geniculocortical projections in Galago senegalensis and Aotus trivirgatus. J Comp Neurol 242:584-610.

Donner KO, Rushton WAH (1959) Retinal stimulation by light substitution. J Physiol (Lond) 149:288-302.

Dow BM, Gouras P (1973) Color and spatial specificity of single units in Rhesus monkey foveal striate cortex. J Neurophysiol 36:79-100.

Dreher B, Fukada Y, Rodieck RW (1976) Identification, classification and anatomical segregation of cells with X-like and Y-like properties in the lateral geniculate nucleus of old-world primates. J Physiol (Lond) 258:433-452.

Dufort PA, Lumsden CJ (1991) Color categorization and color constancy in a neural network model of V4. Biol Cybern 65:293-303.

Estevez O, Spekreijse H (1982) The "silent substitution" method in visual research. Vision Res 22:681-691.

Ferster D (1994) Linearity of synaptic interactions in the assembly of receptive fields in cat visual cortex. Curr Opin Neurobiol 4:563-568.

Foster DH, Nascimento SMC (1994) Relational colour constancy from invariant cone-excitation ratios. Proc $\mathrm{R}$ Soc Lond B Biol Sci 257:115-121.

Gouras P (1970) Trichromatic mechanisms in single cortical neurons. Science 168:489-492.

Granger EM, Heurtley JC (1973) Letters to the editor: visual chromaticity-modulation transfer function. J Opt Soc Am 63:1173-1174.

Hering E (1964) Outlines of a theory of the light sense (Hurvich LM, Jameson D, translators), pp 49-50. Cambridge, MA: Harvard UP.

Hess RF, Norby K (1986) Spatial and temporal limits of vision in the achromat. J Physiol (Lond) 371:365-385.

Hubel DH, Livingstone MS (1990) Color puzzles. Cold Spring Harb Symp Quant Biol 55:643-649.

Hubel DH, Wiesel TN (1959) Receptive fields of single neurones in the cat's striate cortex. J Physiol (Lond) 148:574-591.

Hurlbert A (1999) Colour vision: is colour constancy real? Curr Biol 9:R558-R561.

Ingling CR (1977) The spectral sensitivity of the opponent-color channels. Vision Res 17:1083-1089.

Itten J (1966) The art of color; the subjective experience and objective rationale of color (van Haa E, translator). New York: Reinhol.

Jameson D, Hurvich LM (1959) Perceived color and its dependence on focal, surrounding, and preceding stimulus variables. J Opt Soc Am 49:890-898.

Jameson D, Hurvich LM (1989) Essay concerning color constancy. Annu Rev Psychol 40:1-22.

Kiper DC, Fenstemaker SB, Gegenfurtner KR (1997) Chromatic properties of neurons in macaque area V2. Vis Neurosci 14:1061-1072.

Kraft JM, Brainard DH (1999) Mechanisms of color constancy under nearly natural viewing. Proc Natl Acad Sci USA 96:307-312.

Land EH, McCann JJ (1971) Lightness and retinex theory. J Opt Soc Am 61:1-11.

Lennie P (2000) Color vision. In: Principles of neural science, Ed 4 (Kandel ER, Schwartz, JH, Jessel TM, eds), pp 572-589. New York: McGraw Hill.
Lennie P, Krauskopf J, Sclar G (1990) Chromatic mechanisms in striate cortex of macaque. J Neurosci 10:649-669.

Liebmann S (1926) Uber das Verhalten farbiger Formen bei Helligkeitsgleichheit von Figur und Grund. Psychol Forsch 9:300-353.

Livingstone MS, Hubel DH (1982) Thalamic inputs to cytochrome oxidase-rich regions in monkey visual cortex. Proc Natl Acad Sci USA 79:6098-6101.

Livingstone MS, Hubel DH (1984) Anatomy and physiology of a color system in the primate visual cortex. J Neurosci 4:309-356.

Livingstone MS, Hubel DH (1987) Psychophysical evidence for separate channels for the perception of form, color, movement, and depth. J Neurosci 7:3416-3468.

Livingstone MS, Tsao DY (1999) Receptive fields of disparity-selective neurons in macaque striate cortex. Nat Neurosci 2:825-832.

Livingstone MS, Freeman DC, Hubel DH (1996) Visual responses in V1 of freely viewing monkeys. Cold Spring Harb Symp Quant Biol 61:27-37.

Martin PR, White AJ, Goodchild AK, Wilder HD, Sefton AE (1997) Evidence that blue-on cells are part of the third geniculocortical pathway in primates. Eur J Neurosci 9:1536-1541.

Michael CR (1978) Color vision mechanisms in monkey striate cortex: dual-opponent cells with concentric receptive fields. J Neurophysiol 41:572-588.

Mullen KT (1985) The contrast sensitivity of human colour vision to red-green and blue-yellow chromatic gratings. J Physiol (Lond) 359:381-400.

Ohzawa I, DeAngelis GC, Freeman RD (1997) Encoding of binocular disparity by complex cells in the cat's visual cortex. J Neurophysiol 77:2879-2909.

Poggio GF, Baker FH, Mansfield RJ, Sillito A, Grigg P (1975) Spatial and chromatic properties of neurons subserving foveal and parafoveal vision in rhesus monkey. Brain Res 100:25-59.

Polyak S (1957) The vertebrate visual system, p 260. Chicago: University of Chicago.

Reid RC, Shapley RM (1992) Spatial structure of cone inputs to receptive fields in primate lateral geniculate nucleus. Nature 356:716-718.

Rodieck RW (1991) Which cells code for color? In: From pigments to perception (Valberg A, Lee BB, eds), pp 83- 93. New York: Plenum.

Sandell JH, Gross CG, Bornstein MH (1979) Color categories in macaques. J Comp Physiol Psychol 93:626-635.

Seidemann E, Poirson AB, Wandell BA, Newsome WT (1999) Color signals in area MT of the macaque monkey. Neuron 24:911-917.

Smith VC, Pokorny J (1972) Spectral sensitivity of color-blind observers and the cone photopigments. Vision Res 12:2059-2071.

Smith VC, Pokorny J (1975) Spectral sensitivity of the foveal cone photopigments between 400 and $500 \mathrm{~nm}$. Vision Res 15:161-171.

Spillman L, Werner JS (1990) Visual perception: the neurophysiological foundations, p 55. San Diego: Academic.

Stockman A, Sharpe LT (2000) Tritanopic color matches and the middle- and long-wavelength-sensitive cone spectral sensitivities. Vision Res 40:1739-1750.

Thibos LN, Bradley A, Still DL, Zhang X, Howarth PA (1990) Theory and measurement of ocular chromatic aberration. Vision Res 30:33-49.

Tolhurst DJ, Dean AF (1990) The effects of contrast on the linearity of spatial summation of simple cells in the cat's striate cortex. Exp Brain Res 79:582-588.

Ts'o DY, Gilbert CD (1988) The organization of chromatic and spatial interactions in the primate striate cortex. J Neurosci 8:1712-1727.

Vautin RG, Dow BM (1985) Color cell groups in foveal striate cortex of the behaving macaque. J Neurophysiol 54:273-292.

Wandell BA (1995) Foundations of vision, Appendix B. Sunderland, MA: Sinauer.

Wiesel TN, Hubel DH (1966) Spatial and chromatic interactions in the lateral geniculate body of the rhesus monkey. J Neurophysiol 29:1115-1156.

Zeki (1993) A vision of the brain, plate 16. Cambridge, MA: Blackwell Scientific. 